\title{
ERAD and how viruses exploit it
}

\section{Hyewon Byun, Yongqiang Gou, Adam Zook, Mary M. Lozano and Jaquelin P. Dudley*}

Department of Molecular Biosciences, Center for Infectious Diseases and Institute for Cellular and Molecular Biology, The University of Texas at Austin, Austin, TX, USA

\section{Edited by:}

Shiu-Wan Chan, The University of

Manchester, UK

\section{Reviewed by:}

Yoshitaka Sato, Nagoya University Graduate School of Medicine, Japan Jeanmarie Verchot, Oklahoma State University, USA

\section{${ }^{*}$ Correspondence:}

Jaquelin P. Dudley, Department of Molecular Biosciences, Center for Infectious Diseases and Institute for Cellular and Molecular Biology, The University of Texas at Austin, 2506 Speedway, Stop A5000, NMS 3.316, Austin, TX 78712-1191, USA

e-mail: jdudley@austin.utexas.edu
Endoplasmic reticulum (ER)-associated degradation (ERAD) is a universally important process among eukaryotic cells. ERAD is necessary to preserve cell integrity since the accumulation of defective proteins results in diseases associated with neurological dysfunction, cancer, and infections. This process involves recognition of misfolded or misassembled proteins that have been translated in association with ER membranes. Recognition of ERAD substrates leads to their extraction through the ER membrane (retrotranslocation or dislocation), ubiquitination, and destruction by cytosolic proteasomes. This review focuses on ERAD and its components as well as how viruses use this process to promote their replication and to avoid the immune response.

Keywords: ERAD, immune response, retrotranslocation, ubiquitination, proteasomal degradation, retrovirus, herpesvirus, polyomavirus

\section{INTRODUCTION}

Although endoplasmic reticulum (ER)-associated degradation (ERAD) has been most thoroughly defined in yeast, recent studies in higher organisms have revealed the conservation of this process and its components. Multiple diseases, including Parkinson's, Alzheimer's, cancer, and infectious processes, result from failure of ERAD, confirming its significance for correct cell function. Predictably, viruses have exploited various aspects of this key cellular machinery to further their propagation. Nonetheless, the complexity of ERAD and the number of players involved necessitates a review of its features prior to a description of how viruses have manipulated ERAD to their advantage. In understanding how viruses exploit ERAD, we learn more about the cellular process, but also how we might alter the outcome of viral diseases.

\section{THE ERAD PROCESS}

A majority of newly synthesized proteins in mammalian cells are either misfolded or misassembled (Hoseki et al., 2010). Approximately $30 \%$ of new proteins are synthesized in association with the ER (Brodsky and Wojcikiewicz, 2009). The ER quality control system both senses and disposes of terminally misfolded proteins by ERAD, a process that is conserved in eukaryotes (Vembar and Brodsky, 2008; Merulla et al., 2013). This process detects misfolded proteins in the ER lumen, and then extracts them through membrane channels in an energy-dependent manner for delivery to cytosolic proteasomes (Olzmann et al., 2013). Protein extraction through ER membrane channels is known as dislocation or retrotranslocation (Hampton and Sommer, 2012). Because protein folding depends on multiple cellular components (Merulla et al., 2013), protein overexpression or the presence of mutant proteins may sequester limiting components, leading to accumulation of misfolded proteins in the ER lumen. A more general failure of the ERAD process may occur if proteins are unable to fold within a reasonable time, resulting in inefficient retrotranslocation and proteasomal degradation. Levels of ERAD-associated factors also may be affected by the intraluminal concentration of misfolded proteins. Inability of the ERAD system to destroy misfolded proteins is associated with more than 60 diseases, including neurological illnesses (Alzheimer's and Parkinson's), cystic fibrosis, infectious diseases, diabetes, and cancer (Guerriero and Brodsky, 2012). Particularly relevant to the subject of this review, viruses can produce large quantities of glycoproteins in a short period of time, which may overwhelm ERAD, leading to the accumulation of misfolded proteins, cell death, and associated pathology (Franz et al., 2014).

Although ERAD is vital to the maintenance of healthy cells, many parts of this process are not well characterized. Multiple aspects of ERAD have been described in yeast (Thibault and Ng, 2012), including the nature of the ER channel and the components needed to identify misfolded proteins during and after translation. Protein translocation across the ER membrane is the prerequisite for ERAD. Translation of many transmembrane proteins involves recognition of a hydrophobic signal peptide (SP) emerging from the ribosome by signal recognition particle (SRP), which is associated with the trimeric Sec61 complex. Many of the SPs are cleaved by signal peptidase, which is associated with the luminal side of the translocon (Auclair et al., 2012). The Sec61 complex provides the aqueous channel for co-translational transfer of proteins across the ER membrane (Loibl et al., 2014).

Recent evidence indicates that translocation across the ER membrane can occur through an SRP-independent process (Denic, 2012; Johnson et al., 2013). Based on recent experiments in yeast, more than $40 \%$ of signal-containing proteins fail to use SRP, including tail-anchored (TA) proteins and short secretory proteins (Johnson et al., 2012; Ast et al., 2013). Instead, these proteins are targeted by the GET pathway to the Sec61 translocon that is associated with the Sec 62/63 complex rather than through 
docking to the SRP receptor (Rapoport, 2007; Ast et al., 2013). One large class of SRP-independent proteins includes the glycosylphosphatidylinositol (GPI)-anchored proteins, which contain both an N-terminal signal sequence and a C-terminal GPI anchor (Ast et al., 2013). This N-terminal signal is less hydrophobic than typical SRP targets. Furthermore, the Sec61 translocon has been implicated as the channel for retrotranslocation (Kiser et al., 2001), and it has been proposed that protein transfer can be either forward or reverse with respect to the ER lumen (Johnson and Haigh, 2000). Therefore, Sec61 appears to complex with a number of different proteins, leading to a highly flexible and dynamic structure, where association with different proteins/protein complexes leads to transit in or out of the ER (Figure 1).

\section{SUBSTRATE RECOGNITION FOR ERAD}

Reports in yeast indicate that proteins can be O-mannosylated prior to N-glycosylation (Ecker et al., 2003), and both types of glycosylation are believed to occur co-translationally (Loibl et al., 2014). These glycosylases also have been shown to be associated with the translocon (Chavan and Lennarz, 2006), and experiments indicate competition for different glycosylation sites (Loibl et al., 2014). The protein $O$-mannosyl transferases (PMTs) and the oligosaccharyltransferases (OSTs) are transmembrane proteins, but the latter catalyzes addition of oligosaccharides to nascent polypeptides on asparagine residues (Breitling and Aebi, 2013). The OSTs prefer NxT/S sequences in an unfolded or flexible protein domain, and the unfolded state may be facilitated by the OST complex associated with the translocon (Breitling and Aebi, 2013). Glycosylation near the C-terminal end of the protein is less efficient, perhaps due to competition between OSTs and protein folding (Ben-Dor et al., 2004; Breitling and Aebi, 2013). PMTs also are essential for ERAD in yeast. A $\Delta p m t$ mutant showed increased degradation of a typical ERAD substrate (Arroyo et al., 2011). Moreover, addition of oligosaccharides can be prevented by nearby cysteines and disulfide bond formation (Allen et al., 1995). Thus, glycosylation is one determinant of the correct folding of a protein in the ER lumen (Breitling and Aebi, 2013; Figure 1A).

The oligosaccharides on ER luminal proteins are critical for their correct folding or selection for ERAD. The nascent $\mathrm{N}$-glycosylated protein has a three-branch structure with glucose ${ }_{3}$ mannose $_{9}-\mathrm{N}$-acetylglucosamine ${ }_{2}$-asparagine (Aebi et al., 2010; Merulla et al., 2013). Trimming of the first two glucose residues on one branch then allows interactions with two ER-resident chaperone/lectin proteins, calnexin and calreticulin, which may lead to protein folding (Brodsky, 2012). Removal of the third glucose causes release from these lectins and exit from the ER (Smith et al., 2011; Olzmann et al., 2013), but re-addition of this glucose by UDP-glucose:glycoprotein glucosyltransferase allows reassociation (Shenkman et al., 2013). Proteins retry folding until removal of three or four mannose residues triggers ERAD (Lederkremer and Glickman, 2005; Shenkman et al., 2013). Correctly folded proteins leave the ER after one or two mannose residues have been cleaved (Shenkman et al., 2013). Mannose removal is achieved using ER mannosidase I (ERmanI), the ER degradation-enhancing $\alpha$-mannosidase-like proteins (EDEMs) and/or the Golgi-resident protein Man1C1 (Gonzalez et al.,
1999; Hirao etal., 2006; Olivari et al., 2006; Hosokawa et al., 2007). Several lectins, OS-9 and XTP3-B, then interact via their MRH domains with the mannose-trimmed proteins, allowing their association with the retrotranslocon (Bernasconi et al., 2008; Christianson etal., 2008; Hosokawa etal., 2008). OS9 and XTP3-B also associate with different proteases, LONP2 and carboxypeptidase vitellogenic-like protein (CPVL), respectively, suggesting that some substrates may be partially degraded prior to dislocation (Christianson et al., 2012; Olzmann et al., 2013). Nonetheless, multiple attempts are made to refold proteins before their triage through ERAD. The role of chaperones includes recognition of inappropriate glycosylation as well as refolding efforts, but proteins delivered to the retrotranslocon may require unfolding and partial proteolysis to allow their transit through the narrow membrane channel (Gogala etal., 2014).

Non-glycosylated proteins can be subjected to ERAD, but detection of misfolding of these proteins does not involve calnexin and calreticulin (Brodsky, 2012). Notably, the non-lectin chaperone $\mathrm{BiP}$ is involved in ERAD targeting of both types of proteins (Ushioda et al., 2013), yet also serves to prevent leakage of calcium out of the ER lumen (Schäuble et al., 2012). In addition, targeting of unglycosylated proteins to the proteasomes involves EDEM1 (Shenkman et al., 2013), which, like BiP, recognizes misfolded glycoproteins, as well as the transmembrane Herp protein (Usalp in yeast; Okuda-Shimizu and Hendershot, 2007). Both glycosylated and their non-glycosylated derivatives are recruited to the ERderived quality control compartment (ERQC) near the nucleus in the presence of a proteasomal inhibitor (Shenkman et al., 2013). Thus, these studies suggest that targeting of misfolded proteins for ERAD is similar for glycoproteins and non-glycosylated proteins (Shenkman et al., 2013).

Interaction of lectin-type and other chaperones with ERAD substrates allows association with members of the protein disulfide isomerase (PDI) family, which generally are characterized by one or more thioredoxin-like motifs (CXXC; Brodsky and Skach, 2011). Interestingly, these proteins can form, break, or rearrange disulfide bonds as well as act as chaperones (Benham, 2012). The yeast PDI family is composed of five members (Pdi1, Mpd1, Mpd2, Eug1, and Eps1), although only Pdi1 is essential (Farquhar et al., 1991). In mammalian cells, PDI is one of the best characterized family members, but there are at least 21 such enzymes (Benham, 2012; Grubb et al., 2012). PDI family proteins are generally confined by a KDEL retention sequence (Benham, 2012) to the ER, which has an oxidizing environment (Costantini et al., 2013). The oxidoreductase ERp57, which is localized near the ER-Golgi intermediate compartment (ERGIC), may provide some protection for proteins that might be routed for ERAD by calnexin (Frenkel et al., 2004). In addition, some PDI members can escape the secretory system and appear at the cell surface (Benham, 2012). For example, a disintegrin and metalloproteinase (ADAM17; also known as tumor necrosis factor alpha-converting enzyme or TACE) has been shown to be regulated by an extracellular activity of PDI (Bass and Edwards, 2010; Willems et al., 2010; Düsterhöft et al., 2013). PDI members also have a role in ERAD, with different requirements for different substrates (Grubb et al., 2012). In hepatic cells, PDI promotes the folding of apolipoprotein B (ApoB) 
A

\section{Recognition}

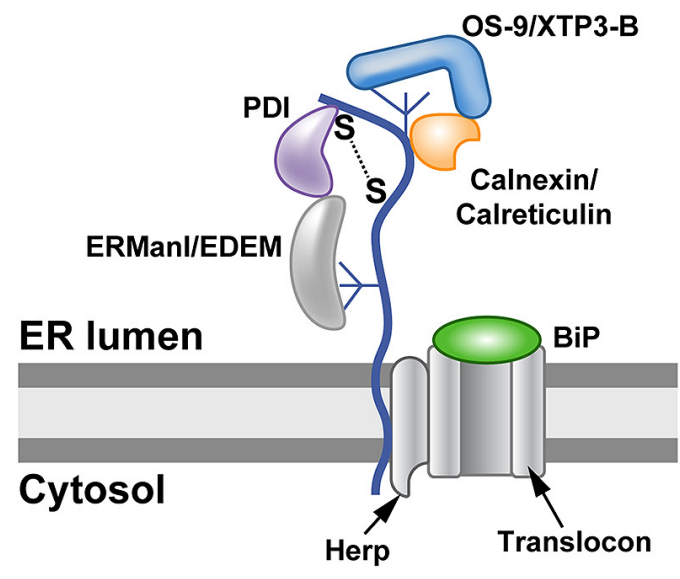

C

\section{Ubiquitination}

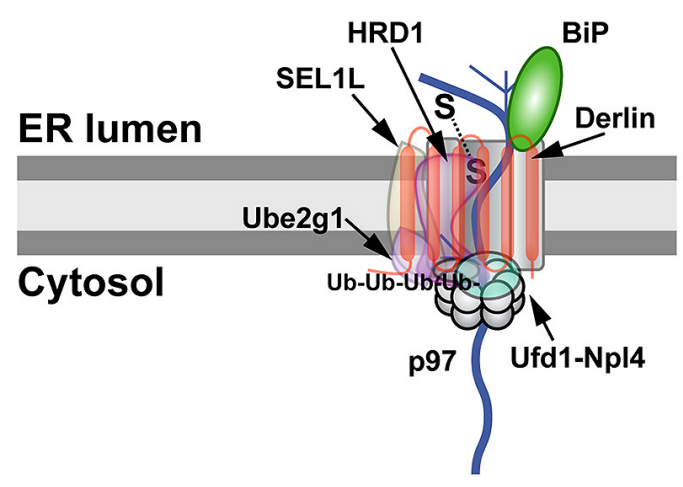

FIGURE 1 |The ERAD process. (A) Substrate recognition. Many nascent polypeptides (curved line) have one or more high-mannose carbohydrates (shown as a branched structure), which must be recognized and processed in a timely manner to allow exit from the ER. Binding of these ER-luminal proteins to substrates is affected by folding to their native conformations. Folding involves formation and breakage of disulfide bonds by members of the PDI family, such as ERp57 and ERp72, and is facilitated by chaperone proteins, such as BiP. Specific carbohydrates are bound by different chaperones/lectins in the ER lumen. These proteins include ERManl, EDEM, OS-9, XTP3-B, calreticulin, and calnexin. Recognition of ERAD substrates probably results in assembly of the retrotranslocon (shown here as Herp and the translocon/BiP complex). Herp is thought to facilitate oligomerization of the Hrd1 E3 ligase. BiP binds to a number of glycosylated and

non-glycosylated ERAD substrates and provides a barrier on the ER luminal side of the translocon. (B) Retrotranslocation. Recognition of misfolded or misassembled proteins triggers the assembly of the retrotranslocon. Current evidence indicates that multiple types of retrotranslocons are possible (see text). A typical retrotranslocon/dislocon is shown containing Derlin, the E3 ligase Hrd1 and its partner Sel1 L, which then recruits the cytosolic ATPase p97. Derlin has 6 transmembrane domains with both the $\mathrm{N}$-terminus and
B

\section{Retrotranslocation}

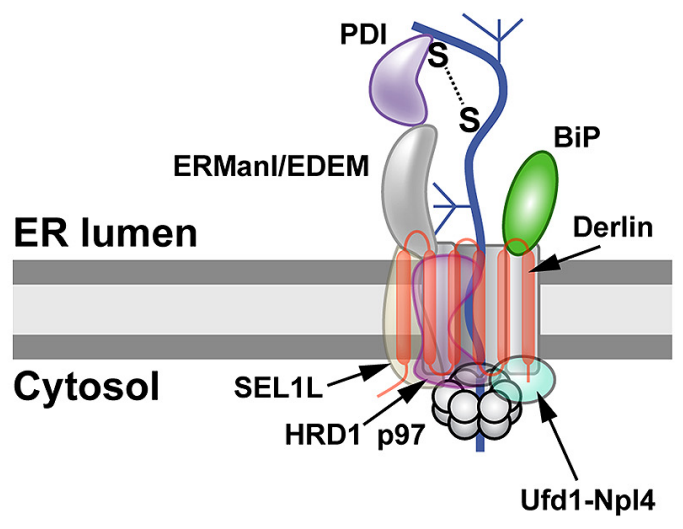

D

\section{Proteasomal Degradation}

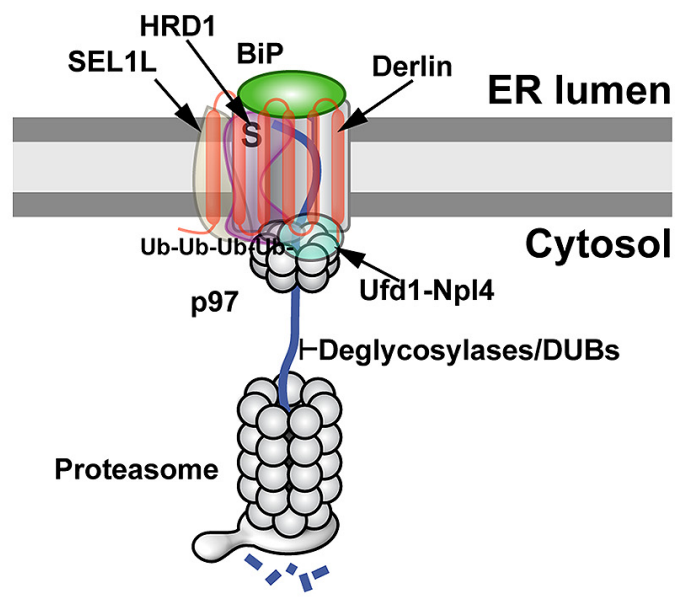

C-terminus in the cytosol. Presumably some or all of the recognition components, such as PDI and ERManl, disengage as the substrate passes through the translocon. All retrotranslocation events appear to involve p97. The retrotranslocon is shown with BiP opening the Sec61 channel for substrate passage into the cytosol. (C) Ubiquitination of ERAD substrates. Retrotranslocation exposes ERAD substrates to cytosolic E1 (unknown), E2 (shown here as Ube2g1), and E3 enzymes (e.g., Hrd1). A polyubiquitin chain is produced as the substrate is engaged by the E2 and E3 proteins. Multiple E3s may be responsible for the polyubiquitin chains that then bind to the p97 partner proteins, Ufd1 and Npl4. The substrate is shown moving through the translocon into the center of the p97 hexamer. (D) Proteasomal degradation. Once the substrate has been retrotranslocated, the BiP protein seals the luminal side of the translocon. The retrotranslocon may then be disassembled prior to engagement of a new substrate. The retrotranslocated proteins must be modified by removal of carbohydrate and ubiquitin chains for insertion into the narrow channel of the proteasome. It is possible that p97 substitutes for the 19S lid, which provides access to the proteasome channel and the energy for unfolding of substrates. Degraded polypeptides are shown emerging from the $19 \mathrm{~S}$ lid. This model suggests that there are retrotranslocon-specific proteasomes. 
through its chaperone activity, whereas ERp57 or ERp72 expression leads to ERAD (Grubb et al., 2012). Further, various cell types express different PDI proteins, allowing differential regulation of substrates (Benham, 2012; Pescatore et al., 2012) and, presumably, their ERAD targeting.

Protein folding involves both formation of disulfide bonds and cis/trans isomerization of peptide bonds preceding proline residues (Hebert and Molinari, 2007). Certain ERAD substrates appear to be dependent on proline isomerization (Bernasconi et al., 2010b), and such refolding events may be necessary for transit through the retranslocon by elimination of turns in substrate secondary structure (Määttänen etal., 2010). ERAD requirements for peptidyl-prolyl cis/trans isomerases (PPIs) depend on whether the substrate is strictly in the ER lumen or is tethered to the ER membrane (Bernasconi et al., 2010b). The PPI protein cyclophilin B was needed for ERAD of a luminal target, but not the same target with a transmembrane domain (Bernasconi et al., 2010b). Requirement for PPIs during ERAD may depend on proline residues in the cis configuration (Bernasconi et al., 2010b), potentially by conversion into trans peptidyl-prolyl bonds, thus eliminating secondary structures that hinder retrotranslocation (Määttänen et al., 2010).

\section{RETROTRANSLOCATION}

Mammalian cells have ERAD factors that are not present in yeast. As observed for other pathways (Tsai and Weissman, 2012), ERAD components identified in yeast have multiple family members in higher eukaryotes; e.g., instead of a single Derlin in yeast (Der1p), mammalian cells have three proteins (Derlin-1, -2, and -3; Oda et al., 2006). Derlins are multiple membranespanning domain proteins that have been proposed to be part of the retrotranslocon channel (Ye et al., 2005) and/or regulatory factors for retrotranslocation (Brodsky, 2012; Figure 1B). In addition, Derlin-3 has a cell-type specific distribution (Oda et al., 2006), suggesting that recognition of certain substrates may be involved in its function. Derlins are related to rhomboid proteases, such as RHBDL4, which is an ER-resident transmembrane protein that cleaves unstable single-membrane-spanning or polytopic membrane proteins (Fleig etal., 2012). RHBDL4 also is upregulated by ER stress and binds to the cytosolic AAA ATPase p97 (see below; Fleig et al., 2012). In contrast to the rhomboid proteases, the Derlins lack proteolytic activity, suggesting that these proteins bind to ERAD substrates and target them to E3 ligases for ubiquitination and to p97 for membrane extraction (Brodsky, 2012). Cleavage of ERAD substrates by RHBDL4 (Fleig et al., 2012), SP peptidase (SPP; Loureiro et al., 2006), or proteases associated with OS-9 and XTP3-B (Olzmann et al., 2013) may occur prior to retrotranslocation of some substrates (Tsai and Weissman, 2012). On the other hand, it has been proposed that Derlins form a six-transmembrane structure with a gate that allows association and unfolding of substrates or access to other retrotranslocon components, such as p97 (see below; Olzmann et al., 2013). The p97 ATPase (Cdc48 in yeast) is bound to Derlin1 and Derlin-2 through their SHP domains (Greenblatt et al., 2011).

Suppressor/enhancer of Lin12-like (SEL1L) appears to link luminal factors that recognize misfolding and inappropriate glycosylation, such as OS-9, XTP3-B, EDEMs, ERdj5, and the PDI protein ERp90, to components of the retrotranslocon (Olzmann et al., 2013; Williams et al., 2013). The transmembrane SEL1L protein ( $\mathrm{Hrd} 3 \mathrm{p}$ in yeast) also participates in regulation of ERAD by sequestering EDEM1 and OS-9 into ER-derived vesicles known as EDEMosomes (Bernasconi et al., 2012a). Inducible knockout of Sel1L in mice leads to death of adult mice from acute pancreatic atrophy (Sun et al., 2014). Sel1L expression is required for stability of the E3 ligase hydroxymethylglutaryl reductase degradation protein 1 (Hrd1), and its loss leads to ER stress and attenuates translation, leading to cell death. Other proteins have been described, such as Erlins 1 and 2 and TMUB1, which may act as adapters between polytopic membrane substrates and E3 ligases (Olzmann et al., 2013).

\section{UBIQUITINATION}

The ubiquitin ligases (E3s) have been proposed to be a structural part of the retrotranslocon channel (Brodsky, 2012), but their role is considerably more complex (Figure 1C). Several E3 ligases associated with ERAD are multiple membranespanning proteins with cytosolic RING domains (Smith et al., 2011; Ruggiano et al., 2014). In yeast, where ERAD has been studied most extensively, a prototypical transmembrane E3, such as Hrd1p (also called SYVN1; Nadav et al., 2003; Kikkert et al., 2004), can promote ERAD of a luminal substrate (ERAD-L). The ERAD process also involves Hrd3p (SEL1L in metazoans) as well as Usalp and Der1p (Carvalho et al., 2010). Herp may assist with Hrd1 oligomerization (Carvalho et al., 2010), Nevertheless, the other components appear to be dispensable if Hrdlp is overexpressed, consistent with a role for Hrdlp in ERAD substrate transfer across the membrane (Carvalho et al., 2010), although such overexpression may be toxic due to inappropriate protein degradation (Denic et al., 2006). Thus, protein adapters appear to be necessary to achieve substrate specificity (Smith et al., 2011).

Hrd1p-mediated ERAD requires oligomerization and transmembrane domains as well as ubiquitin ligase activity (Carvalho et al., 2010). Overexpression of a dominant-negative RING mutant of the HRD1 ligase prevented ERAD of a non-glycosylated substrate, but a dominant-negative Fbs2 mutant (a component of SCF E3 ligases) did not (Shenkman et al., 2013). Dependence on HRD1 also is affected by tethering of the substrate to the ER membrane. Splice variants of the human beta-site amyloid precursor cleaving enzyme (BACE) with the same deletion mutation in the ectodomain are degraded through HRD1 if they are luminal (ERAD-L substrates), but disposal occurs in a HRD1independent manner if the variant has a transmembrane domain (ERAD- $\mathrm{L}_{\mathrm{M}}$ substrates; Bernasconi et al., 2010a). Therefore, HRD1 recognizes substrates for ubiquitination and, perhaps, modifies the translocon in the ER membrane.

Multiple E3 ligases participate in ERAD. These ligases include the transmembrane proteins gp78/AMFR (Fairbank et al., 2009), TRC8 (Stagg et al., 2009), RMA1/RNF5 (El Khouri et al., 2013), MARCH6/TEB4 (Doa10 in yeast; Kreft and Hochstrasser, 2011; Olzmann et al., 2013), and CHIP (Matsumura et al., 2013). An additional 40-50 membrane-spanning E3s may be involved in ERAD (Stagg et al., 2009). Other E3 ligases associated with ERAD 
are localized to the cytosol, where they recognize misfolded glycoproteins that already have been retrotranslocated (Yoshida et al., 2005; Shenkman et al., 2013). These ubiquitin ligases are members of the cytosolic SCF (S-phase kinase-associated protein 1 (Skp1)Cullin 1 (Cul1)-F-box) family, where the F-box components of the SCF complex recognize the N-glycans of the retrotranslocated substrate, e.g., Fbs1 and Fbs2 (Yoshida, 2007). Furthermore, E3s may work together to direct substrates for degradation (Olzmann et al., 2013).

\section{PROTEASOMAL DEGRADATION}

The p97 protein (Cdc48 in yeast) is a member of the AAA ATPase family (Erzberger and Berger, 2006) that functions during ERAD in a complex with several cofactors that have a ubiquitin-X (UBX) or UBX-like domain (Schuberth and Buchberger, 2008; Figure 1). These cofactors include the heterodimer nuclear protein localization homolog 4 (Npl4)-ubiquitin fusion degradation 1 (Ufd1; Meyer et al., 2012; Wolf and Stolz, 2012), p47, UBXD1, UBXD7, Ufd3/PLAA, VCIP135, and Ataxin-3 (Meyer et al., 2012). The UFD1L and NPL4 proteins are believed to form a heterodimer, where NPL4 is needed to stabilize UFD1L (Nowis et al., 2006). The heterodimer acts as a substrate adapter to the p97 ATPase associated with the retrotranslocon (Bays and Hampton, 2002). UFD1L and NPL4 bind to K48-linked and K63-linked polyubiquitin chains, respectively, which have been added by E3 ligases associated with the retrotranslocon (Ye et al., 2003; Komander et al., 2009).

In yeast, the Cdc48 ATPase binds to the Hrd1 E3 ligase in a RING-dependent manner (Hampton and Sommer, 2012), and the transmembrane Ubx2 (Sel1) protein acts as an adapter using a UBA domain (Neuber et al., 2005; Schuberth and Buchberger, 2005). Several other ubiquitin ligases bind p97 directly or through cofactors (Alexandru et al., 2008). The p97 cofactors act as ubiquitin-binding proteins, although p97 also has ubiquitin-binding activity (Ye etal., 2003; Meyer et al., 2012). The adapter-p97 complexes may recognize different substrates and perform independent functions, such as membrane protein segregation and trafficking, as well as directing substrates to the proteasome (Ritz et al., 2011). Alternatively, other models suggest that Derlins are involved in unfolding of substrates as well as providing contacts with p97 and its associated factors (Greenblatt et al., 2011). The p97 ATPase binds ubiquitin chain editors that can extend shorter chains as well as deubiquitinating enzymes (DUBs; Jentsch and Rumpf, 2007; Sowa et al., 2009). Two ATPase domains (D1 and D2; Meyer et al., 2012) within p97 form two stacked hexameric rings that provide the energy for protein remodeling and substrate extraction from the membrane or through the retrotranslocon (Hampton and Sommer, 2012). Mutations in the D2 domain result in dominant-negative proteins that bind, but fail to release, substrates (Pye et al., 2006). Mutant proteins have been widely used to study p97 function in ERAD and its myriad other activities (Meyer et al., 2012). Cytosolic chaperones, such as Hsp70, also may provide energy for extraction of membrane proteins with misfolded cytoplasmic domains (ERAD-C substrates; Taxis et al., 2003; Hrizo et al., 2007).

Once extraction from the ER membrane has occurred, p97 recruits peptide $\mathrm{N}$-glycanase (PNGase) to cleave $\mathrm{N}$-linked glycans from glycosylated substrates (Hirsch et al., 2003; Li et al., 2006; Figure 1D). In addition, p97 binds to a deubiquitinating enzyme YOD1, presumably so that polyubiquitin chains will not interfere with insertion into the proteasome (Ernst et al., 2009). The proteasome is a highly complex structure with a $19 \mathrm{~S}$ lid that has an ATPase activity very similar to that of p97 (Lipson et al., 2008; Matouschek and Finley, 2012). These enzymes may function synergistically to deliver substrates to the 20S core (Hampton and Sommer, 2012). Alternatively, p97 may deliver certain substrates directly to the proteasome core (Matouschek and Finley, 2012). The proteasome core is composed of 28 subunits arranged into four rings, each composed of seven subunits (Bhattacharyya et al., 2014). Proteolytic activity is sequestered in the center of a narrow chamber formed by the rings and, therefore, only unfolded proteins can enter the chamber (Groll et al., 2000). The 19S lid, p97, or other activators provide docking for substrates and substrate modifying proteins as well as regulated opening of the chamber to allow access of unfolded proteins for degradation in the 26S core (Bhattacharyya et al., 2014).

Many questions remain about ERAD components and how they identify and interact with different substrates. Similar to our analysis of other cellular and molecular biological processes through virology, studies of viruses that use ERAD are likely to prove insightful.

\section{VIRAL MANIPULATION OF THE IMMUNE RESPONSE BY ERAD}

The ability of viruses to cause persistent infections is a consequence of downregulation or subversion of the immune response. The herpesviruses are known to cause persistent infections. One well-studied example of herpesvirus manipulation of the immune response is reduced cell expression of major histocompatibility complex class 1 (MHC-I) molecules by the viral proteins US2 and US11 (Wiertz etal., 1996). Both proteins are transmembrane glycoproteins and bind to newly made MHC-I to initiate retrotranslocation. Despite their similar function, US2 and US11 use different pathways for MHC-I degradation (Figure 2). US2mediated degradation of MHC-I is independent of Derlin-1 and involves SPP (Loureiro et al., 2006), which cleaves many SPs following their removal from nascent ER-bound pre-proteins (Voss et al., 2013). Using an siRNA screen, TRC8 was identified as the E3 ligase involved in MHC-I degradation by US2, but knockdown of this transmembrane RING-type E3 had no effect on US11mediated destruction of MHC-I (Stagg et al., 2009). The US2 cytosolic tail interacts with SPP and the p97 ATPase (Chevalier and Johnson, 2003; Loureiro et al., 2006), whereas TRC8 and US2 bind through their transmembrane domains (Stagg et al., 2009; Figure 2A).

Unlike the Derlin-independent mechanism proposed for US2, studies of the US11 protein facilitated identification of Derlin-1 and SEL1L as ERAD components (Figure 1; Lilley and Ploegh, 2004; Ye et al., 2004; Mueller et al., 2006). US11 does not require SPP for MHC-I degradation (Loureiro et al., 2006), but appears to interact with the E3 ligase MARCHVII/axotrophin (Flierman et al., 2006). The cytosolic domain of MHC-I is required for US11mediated ERAD targeting (Story et al., 1999; Barel et al., 2003), and deletion of the C-terminal valine of MHC-I reduced interaction with Derlin-1 (Cho et al., 2013a). The ER luminal domain 


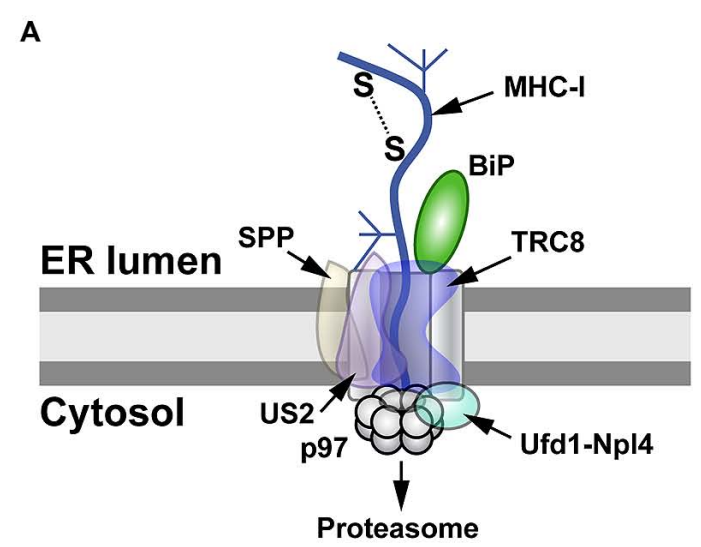

FIGURE 2 | MHC-I degradation by the herpesvirus US2 and US11 proteins. (A) Retrotranslocation of MHC-I by US2. US2 targets MHC-I molecules for retrotranslocation by a process that requires signal peptide peptidase (SPP), the E3 ligase TRC8, and the Ufd1-Npl4-p97 complex. SPP may induce partial degradation of the substrate prior to its proteasomal

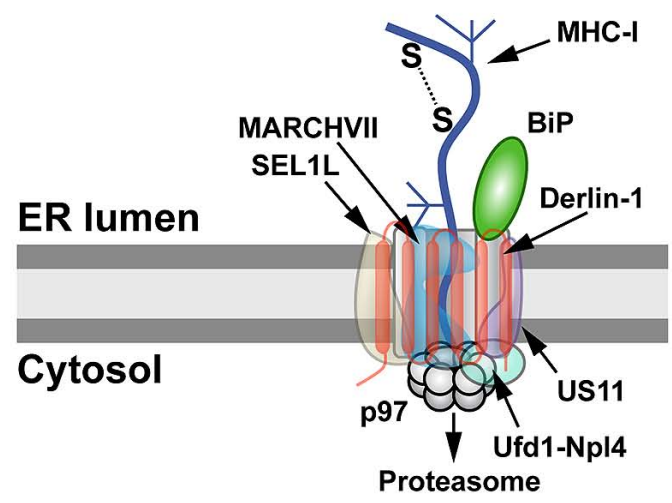

entry. (B) Retrotranslocation of MHC-I by US11. MHC-I is retrotranslocated after US11 recruits SEL1L, Derlin-1, the E3 ligase MARCHVII, and p97. It is not clear whether either degradation of MHC-I by US2 or US11 involves the adapter complex Ufd1-Npl4, which recognizes different types of polyubiquitin chains. also affects degradation (Barel et al., 2003). In addition, MHCI substituted with the transmembrane domain of US11 caused interaction with Derlin-1 and proteasomal degradation (Cho et al., 2013b). The p97 ATPase does not appear to interact directly with MHC-I, but requires the interaction of MHC-I cytosolic domain with the C-terminal domain of Derlin-1 (Cho et al., 2013a). Cho et al. speculated that US11 recognizes MHC-I through its cytosolic domain and transfers it to Derlin-1, which then interacts with the p97 ATPase for membrane dislocation (Cho et al., 2013a; Figure 2B). Therefore, studies of the herpesvirus US2 and US11 proteins revealed that the same substrate does not always use the same ERAD pathway, and presumably these viral proteins act as adapters that recognize different parts of MHC-I for targeting to the dislocon.

Herpesviruses use another mechanism to decrease levels of MHC-I. The mouse gammaherpesvirus 68 (MHV68) encodes an E3 ligase (mK3) that ubiquitinates newly made MHC-I heavy chains for proteasomal degradation (Boname and Stevenson, 2001). The $\mathrm{mK} 3$ ligase also is associated with the transporterassociated with antigen processing (TAP) as well as p97 and Derlin-1 (Wang et al., 2006). Polyubiquitination of MHC-I did not require lysines (Wang et al., 2005), but could occur on serine and threonine residues in the heavy chain C-terminal tail via the recruitment of the Ube2j2 E2 enzyme (see Figure 1; Wang et al., 2007, 2009; Herr et al., 2009). These data indicate that multiple ERAD mechanisms can be used by viruses to diminish the adaptive immune response.

Like the herpesviruses, retroviruses also manipulate the immune system through ERAD. Early studies indicated that human immunodeficiency virus type 1 (HIV-1)-infected cells had decreased levels of both CD4 mRNA and protein (Hoxie et al., 1986). CD4 acts as the receptor for binding the viral envelope (Env) protein (McClure et al., 1987). Furthermore, CD4 participates in T-cell activation by binding to both the T-cell receptor and MHC class II molecules on antigen-presenting cells. CD4+ T cells secrete cytokines that control antibody production, phagocytic cell function, and cytotoxic T-cell responses, making them crucial for adaptive immune responses (Tubo and Jenkins, 2014). HIV-1 encodes a number of accessory proteins, including $\mathrm{Vpu}$, which are not required for virus replication in tissue culture, but contribute to viral pathogenesis (Strebel, 2013). Expression of Vpu and CD4 by transient transfection showed dramatic decreases in CD4 levels, and CD4 depletion was dependent on serines 52 and 56 in Vpu (Magadán et al., 2010).

Vpu-induced CD4 degradation has been shown to involve the ERAD system. Knockdown of both $\beta$-TrCP1 and $\beta$-TrCP2 largely prevented Vpu-mediated CD4 loss (Magadán et al., 2010). $\beta$-TrCP1 and $\beta$-TrCP2 (also known as FBW1A, FBXW1, FBXW1A, or FWD1) are F-box proteins containing WD40 domains, which are associated with the SCF family of ubiquitin ligases (Figure 3 ). These protein complexes are linked to regulation of multiple pathways involving cell cycle checkpoints, NFKB, and Wnt (Skaar et al., 2013). In addition, knockdown of p97, UFD1L (also called Ufd1) or NPL4 (see Figure 1C) blocked depletion of CD4 (Magadán et al., 2010). Mutations that prevented ATP binding or hydrolysis by p97 failed to affect CD4 levels (Magadán et al., 2010). These experiments indicated that Vpu uses ERAD to degrade CD4, but also prevents cell surface expression by retaining CD4 in the ER, probably through transmembrane domain interactions (Magadán et al., 2010). Moreover, Vpu used an atypical E3 ligase to induce ERAD (Margottin et al., 1998), and this process involved $\mathrm{SCF}^{\beta-\mathrm{TrCP}}$ ubiquitination of the CD4 cytosolic tail on lysine, serine, and threonine residues (Magadán et al., 2010). Thus, Vpu may act as an adapter between CD4, retrotranslocon components, and a cytosolic E3 ligase. CD4 degradation promotes HIV-1 infection by preventing re-infection, facilitating virus release by avoiding Env-CD4 interactions during their trafficking to the cell surface, and minimizing adaptive immune responses (Lanzavecchia et al., 1988; Willey et al., 1992; Argañaraz et al., 2003).

HIV-1 Vpu also targets another cellular protein, tetherin/BST2, for ERAD (Neil et al., 2008; Mangeat et al., 2009). Tetherin is an unusual type II membrane protein with an N-terminal 


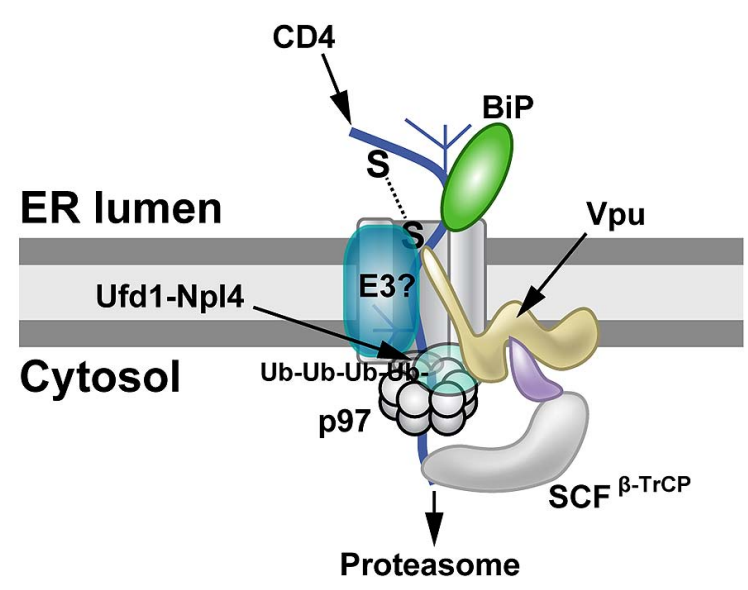

FIGURE 3 | Proteasomal targeting of CD4 by HIV-1 Vpu. The

transmembrane protein $\mathrm{Vpu}$ recruits the E3 ligase complex SCF ${ }^{\beta-T r C P}$. Knockdown of both $\beta$-TrCP1 and $\beta$-TrCP1 (shown to be contacting Vpu) can prevent CD4 degradation, suggesting that either F-box protein can provide a functional SCF complex for ubiquitination (Magadán et al., 2010). Another E3 ligase (E3?) also may be involved. The p97 ATPase with the adapters Ufd1 and Npl4 are required for CD4 degradation, but the UFD1L protein recognizes polyubiquitinated CD4. Lysine and serine/threonine residues in the CD4 cytosolic tail are needed for ubiquitination (Magadán et al., 2010).

transmembrane segment and a C-terminal GPI anchor (Kupzig et al., 2003; Sauter, 2014). Moreover, two tetherin monomers are bound together by disulfide bonds (Ishikawa et al., 1995; Kupzig et al., 2003). Using a unique method that only allows biotinylation of retrotranslocated molecules by cytosolic BirA protein, recent experiments indicate that both CD4 and tetherin remain glycosylated and retain disulfide bonds during retrotranslocation (Petris et al., 2014). These data suggest that the typical Sec61 channel used for translocation is insufficiently wide to accommodate retrotranslocation substrates modified with these structures (Petris et al., 2014), but an alternative model involving lipid droplet formation has not been confirmed (Olzmann and Kopito, 2011). Given the large number of proteins that have been implicated, a single mechanism for retrotranslocation is unlikely. Despite common delivery of substrates to the proteasome via the p97 ATPase, each of the previous examples of viral ERAD targeting involves different E3 ligases.

Recent evidence suggests that ERAD can target the retrovirus HIV-1 Env (Zhou et al., 2014), a glycosylated transmembrane protein. Studies of a human CD4+ T-cell line CEM.NKR indicated that HIV-1 replication is restricted in these cells, which also are resistant to natural killer cell-mediated lysis (Howell et al., 1985). Surprisingly, these cells overexpressed a mitochondrial translocator protein, TSPO (Braestrup and Squires, 1977; Papadopoulos et al., 2006), and knockdown or knockout of this protein rescued Env and HIV-1 production (Zhou et al., 2014). Further experiments indicated that drugs inducing ERAD led to recovery of Env levels and viral titers. These results suggested that the ER and mitochondria communicate through juxtaposition of their membranes, so that conditions in the mitochondria influence protein folding and ERAD. In support of this conclusion, gp78 is an ERAD-associated E3 ligase (Fang et al., 2001) localized to mitochondria-ER membrane contacts (Fu etal., 2013). Thus, mitochondria proteins may influence ERAD and modulate HIV-1 Env presentation to the immune system.

Triggering of an innate immune response to viruses is affected by the ERAD process. Some anti-viral signaling is controlled through mitochondria, which also cooperates with the ER for lipid synthesis and calcium-controlled processes at the mitochondrialassociated membrane (MAM; Jacobs et al., 2014). Mitochondrial antiviral signaling protein (MAVS; also called IPS-1, VISA, or CARDIF) binds to different retinoic acid-inducible gene-I (RIGI)-like receptor (RLR) proteins, which sense cytosolic viral RNAs (Kawai et al., 2005; Meylan et al., 2005; Seth et al., 2005; Xu et al., 2005). The MAVS protein is present in the mitochondrial and peroxisomal membranes, and viral RNA triggers both interferondependent or independent responses, respectively, (Jacobs and Coyne, 2013; Jacobs et al., 2014). The levels of MAVS are affected by gp78, an E3 ubiquitin ligase that is localized to the ERmitochondrial interface (MAM; Jacobs et al., 2014). The gp78 ligase was detected by a high throughput RNAi screen to identify genes that restricted enterovirus replication (Coyne et al., 2011). Downregulation of gp78 was shown to decrease yields of vesicular stomatitis virus (VSV) and to increase type I interferon responses.

Some viruses, such as those inducing hepatitis $\mathrm{B}(\mathrm{HBV})$ or $\mathrm{C}$ (HCV), use ERAD to reduce the amounts of glycoproteins and particles produced. Interestingly, both viruses partially induce the unfolded protein response (UPR; Li et al., 2007, 2011; Saeed et al., 2011), which then increases the levels of certain ERAD components. HBV, a member of the Hepadnaviridae, triggers upregulation of the glycoside hydrolase 47 family enzymes, EDEM 1 and 2. Increased EDEM levels appear to bypass normal ER folding of HBV glycoproteins to result in ERAD (Lazar et al., 2012). $\mathrm{HCV}$, a member of the Flaviviridae, induces primarily EDEM1 through the UPR and splicing of X-box binding protein 1. Further experiments suggested that elevated levels of EDEM 1 and 3 increase binding to SEL1L, an adapter to the retrotranslocon (Figure 1). Inhibition of EDEM binding to SEL1L interfered with ubiquitination of HCV Env protein, E2 (Saeed et al., 2011). Interestingly, infections by another member of the Flaviviridae, Japanese encephalitis virus, did not result in EDEM binding to the Env proteins, indicating that not all viral family members control Env proteins by this mechanism. Overall, manipulation of EDEM levels appears to be a common mechanism to reduce viral glycoprotein levels. Lowered amounts of Env proteins and virus particles then contribute to avoidance of innate and adaptive immunity, leading to chronic infections (Saeed et al., 2011; Lazar et al., 2012).

\section{VIRAL ESCAPE FROM ERAD}

A number of pathogens harness the ERAD process to facilitate various replication strategies. The best known examples are the bacterial AB toxins, particularly cholera toxin, which is thought to hijack the ERAD machinery for delivery to the cytosol (Hazes and Read, 1997). Cholera toxin has a catalytic A chain divided into two subunits (CTA1 and CTA2) inside a pore composed of five receptor-binding B subunits (Spangler, 1992). The holotoxin 
binds to the ganglioside GM1 on the surface of gut epithelial cells, which then triggers toxin internalization and trafficking through the Golgi to the ER (Fujinaga et al., 2003). The A subunits are bound to the B subunits by disulfide bonds, and the toxin complex interacts with the ER-resident enzyme PDI (Figure 1). PDI is a redox-dependent chaperone that unfolds the toxin, which is then released in the oxidized state (Tsai et al., 2001). This unfolding event appears to be required for the ability of CTA1 to retrotranslocate to the cytosol, where it induces the ADP-ribosylation of the Gas protein and, ultimately, opening of chloride channels leading to massive diarrhea (Muanprasat and Chatsudthipong, 2013).

As noted above, retrotranslocation of ERAD substrates is preceded by a recognition step. The chaperone BiP, which is known to be involved in identification of non-glycosylated ERAD substrates, and an ER-resident ATPase (Torsin A) promote CTA1 retrotranslocation (Tsai et al., 2001; Winkeler et al., 2003; Forster et al., 2006; Moore et al., 2010). Sel1L and ERdj5, a co-chaperone of BiP, also facilitate CTA1 retrotranslocation, where the J domain of ERdj5 is required (Williams et al., 2013). ERdj5 also binds to Sel1L, likely providing interaction with the Hrd1 E3 ligase (see Figure 1). Torsin A may provide the link to the membrane-resident Derlin1 protein (Nery etal., 2011). CTA1 retrotranslocation appears to involve Derlin-1 (Bernardi et al., 2008) and the transmembrane ubiquitin ligases, Hrd1 and gp78 (Bernardi et al., 2010). Thus, multiple low affinity interactions are likely involved in the identification of CTA1 as a substrate and its delivery to the retrotranslocon.

Similar to other retrotranslocated substrates, the cytosolic p97 ATPase participates in CTA1 extraction from the ER membrane (Abujarour et al., 2005; Kothe et al., 2005). Nevertheless, CTA1 subverts the normal ERAD process by avoiding polyubiquitination (Rodighiero et al., 2002). The hypothesis that CTA1 avoids ubiquitination through the absence of lysines targeted for polyubiquitination was not substantiated by mutational analysis (Rodighiero et al., 2002). These results indicate that CTA1 employs many of the typical components used for ERAD targeting, including the E3 ligase, but it is unclear how polyubiquitination and degradation of the substrate are avoided. Therefore, retrotranslocon targeting and substrate extraction from the ER membrane is not necessarily coupled to ubiquitination, although ubiquitination may be required for proteasomal degradation.

Viral pathogens also use ERAD. Mouse mammary tumor virus (MMTV) is a betaretrovirus that subverts the ERAD process to complete its viral replication cycle. All retroviruses synthesize an unspliced viral RNA that requires export from the nucleus to the cytosol for translation or packaging into virus particles (Cullen, 2003). The unspliced RNAs of simple retroviruses have a highly structured cis-acting sequence, such as the constitutive transport element (CTE) of Mason-Pfizer monkey virus (MPMV; Bray et al., 1994). The CTE facilitates RNA export through the typical TAP/NXF1-mediated pathway used by cellular mRNAs (Grüter et al., 1998). In contrast, the complex retroviruses encode an adapter protein, such as the Rev protein of HIV-1 (Hanly et al., 1989), which binds to a structured RNA element near the $3^{\prime}$ end of the genome (Daly et al., 1989; Zapp and Green, 1989). MMTV also produces a Rev-like protein, Rem, for export of unspliced RNA
(Mertz et al., 2005), but Rem binding to viral RNA has additional translation-associated functions (Mertz et al., 2009b).

Unlike other complex retroviruses, Rem is made from an internally deleted form of the Env protein, and the export function resides in a long SP of 98 amino acids (Indik et al., 2005; Mertz et al., 2005). Interestingly, Rem is a precursor protein that is directed to the ER membrane for translation, where it appears to be cleaved by signal peptidase into the Rev-like Rem-SP and a C-terminal glycosylated product (Rem-CT) of unknown activity (Byun et al., 2010). Recent evidence indicates that Rem-SP uses retrotranslocation for extraction from the ER membrane, but, like cholera toxin, avoids proteasomal degradation (Byun et al., 2010, 2012).

Dultz et al. (2008) first reported that Rem is directed to the ER membrane for translation and cleavage by signal peptidase. They also suggested that the Rem precursor (the uncleaved protein) could be detected in the nucleus by fluorescence microscopy (Dultz et al., 2008). Byun et al. (2010) showed that mutation of the predicted signal peptidase cleavage site prevented the appearance of Rem-SP as detected by both Western blotting and a highly sensitive reporter assay for Rev-like function (Mertz et al., 2005; Byun et al., 2010). This assay requires binding to a specific RNA element in viral RNA (Müllner et al., 2008; Mertz et al., 2009a). Fluorescence experiments indicated that only the cleaved Rem-SP enters the nucleus, whereas the uncleaved form was highly unstable and localized to the cytosol (Byun et al., 2010). Furthermore, RemSP activity was inhibited by expression of a dominant-negative form of the p97 ATPase required for retrotranslocation (Byun et al., 2010). Rem-SP function also was reduced by the expression of a dominant-negative Derlin-1, but not Derlin-2 protein (Byun et al., in preparation). These results strongly suggest that Rem must be cleaved by signal peptidase prior to SP retrotranslocation to the cytosol and import into the nucleus for RNA binding (Figure 4).

Experiments indicate that an altered conformation of either the $\mathrm{N}$-terminal Rem-SP in the cytosol or the ER-luminal portion of Rem affect folding and accessibility to signal peptidase, which is associated with translocons (Falk and Gilula, 1998). First, Rem tagging at the C-terminus with green fluorescent protein (RemGFP) resulted in a stable protein that was inefficiently cleaved and had little fluorescence (Mertz et al., 2005; Byun et al., 2012). Rem-GFP also had very low functional activity in reporter assays (Mertz et al., 2005). In contrast, Rem tagged at the N-terminus with GFP was cleaved normally, and GFP-Rem-SP localized to the nucleoli, a result typical of other Rev-like proteins (Cullen, 2003; Mertz et al., 2005). Second, deletion mutations of the Rem C-terminus greatly affected stability of the protein (Byun et al., 2012). Removal of the $50 \mathrm{C}$-terminal amino acids had little effect on the cleavage or stability of the protein, but deletion of 100 or 150 amino acids produced a highly unstable precursor that could be rescued by the proteasomal inhibitor MG-132 (Byun et al., 2012). Reduced cleavage of the precursor also was observed. Surprisingly, further deletion to give only the SP (Rem-SP) again yielded a stable protein (Byun et al., 2012). Third, substitution of the leucine at position 71 in the SP gave a stable precursor protein that was poorly cleaved by signal peptidase (Mertz et al., 2009a; Byun et al., 2010). An independent report indicated that residues 


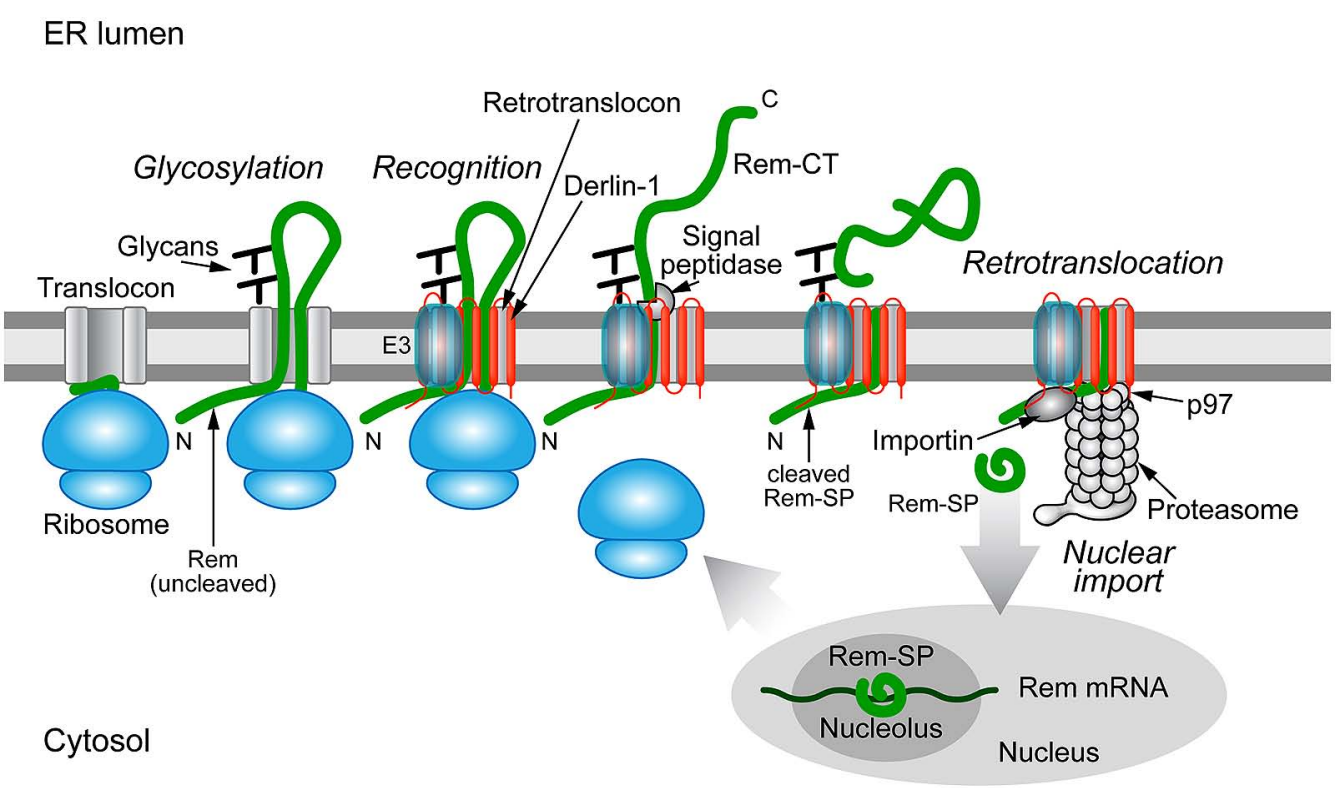

FIGURE 4 | Trafficking of the MMTV Rem protein by subversion of ERAD. Rem is a precursor protein that has an N-terminal signal peptide (Rem-SP) that directs translation to the ER membrane. The Rem-CT enters the ER lumen, where it is modified by $\mathrm{N}$-glycosylation on two different sites. Rem recognition for retrotranslocation is not understood, but appears to involve Derlin-1 and, potentially, an E3 ligase, although ubiquitinated Rem has not

80 through 98 act as the hydrophobic membrane anchor sequence, suggesting that position 71 is localized in the cytosol (Dultz et al., 2008). Recognition of Rem C-terminal sequences in the ER lumen, presumably by their interaction or lack of interaction with specific chaperone proteins, prevent degradation by ERAD.

The ER-luminal chaperone BiP has repeatedly been detected after purification and proteomic analysis of Rem-binding proteins (Gou et al., manuscript in preparation). Our preliminary data indicate that Rem-SP is not ubiquitinated, and it is possible that this feature protects Rem-SP from proteasomal degradation. Since the Rem precursor and C-terminal deletion mutants are subject to ERAD, cleavage and association with specific cellular proteins appear to be critical for avoidance of the degradative process. The idea that viral proteins manipulate E3 enzymes to form alternative complexes (Olzmann et al., 2013) would be consistent with Rem-SP escape from ERAD.

The polyomaviruses have a unique entry method that uses retrotranslocation, while avoiding ERAD. The BK polyomavirus (BKV) first binds to the ganglioside receptors GT1b and GD1b and enters through caveolae (Neu et al., 2009), which are composed of membrane microdomains/lipid rafts that are enriched for sphingolipids and signaling molecules (Head et al., 2014; Figure 5). Particle delivery to the cytosol occurs through a $\mathrm{pH}$ dependent step involving endosomal trafficking via microtubules to the ER (Eash and Atwood, 2005; Moriyama and Sorokin, 2008; Jiang etal., 2009). Other members of the Polyomaviridae use caveolae-independent entry for ER delivery (Neu et al., 2009). ER localization of these viruses is necessary to access specific retrotranslocation components. been observed. Full-length Rem is cleaved by signal peptidase, and Rem-CT is released into the ER lumen. Similar to other retrotranslocation substrates, Rem-SP is extracted from the ER membrane using the p97 ATPase. Despite its dislocation into the cytosol, Rem-SP escapes the proteasome and translocates into the nucleus for binding of MMTV RNA. This figure is adapted from Byun etal. (2012).
The VP1 capsid proteins of polyomaviruses form pentamers during assembly that are held together by disulfide bonding ( $\mathrm{Li}$ et al., 2003). Each pentamer is associated with one molecule of either the minor capsid protein VP2 or VP3 (Barouch and Harrison, 1994), which become accessible to antibodies after exposure to the unique environment of the ER (Norkin et al., 2002). Particle delivery into the ER allows reduction and isomerization of disulfide bonds using ERp29 (mouse polyomavirus; Magnuson et al., 2005) or ERp57 and PDI (SV40; Schelhaas et al., 2007) to allow partial uncoating (Jiang et al., 2009; Tsai and Qian, 2010). The partially uncoated virion then engages the retrotranslocation machinery to allow cytosolic entry similar to cholera toxin (Neu et al., 2009).

Interestingly, different polyomaviruses use distinct Derlin family members for retrotranslocation. SV40 uses Derlin-1 and SEL1L (Schelhaas et al., 2007), whereas mouse polyoma virus uses Derlin2 (Lilley et al., 2006; Figure 5). Additional experiments indicate that exposure of VP2 hydrophobic sequences tethers virus particles to the ER membrane, and that both BiP and BAP31 are needed for dislocation of SV40 to the cytosol (Geiger et al., 2011). BAP31 may serve as a shuttle to the ERQC that has been associated with enriched ERAD components (Kamhi-Nesher et al., 2001; Wakana et al., 2008). Furthermore, use of epoxomicin or eeyarestatin 1, inhibitors of the proteasome or p97 ATPase, respectively, blocked early events of BKV infection (Bennett et al., 2013). Epoxomicin treatment of cells allowed accumulation of BKV in the calnexin-rich, BiP-deficient ERQC (Bennett et al., 2013). These results are consistent with ERAD extraction of polyomaviruses from the ER to the cytosol, although it is has been suggested that 


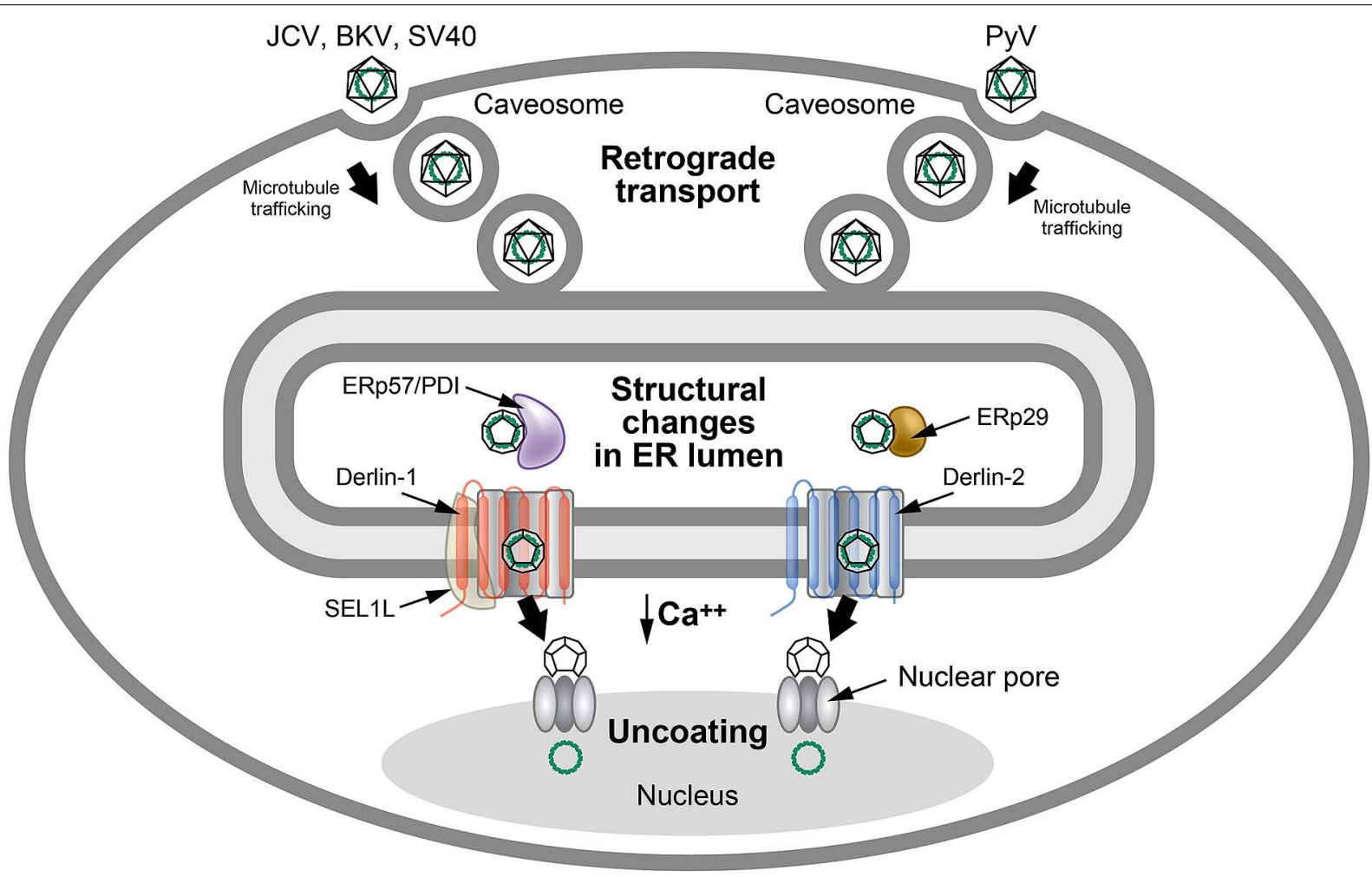

FIGURE 5 | Use of ERAD for polyomavirus uncoating. Many polyomaviruses enter through caveosomes that are enriched for viral entry receptors, triggering particle uptake through endosomes. Using the microtubule network, vesicles traffic the virus to the ER, where the unique environment allows structural changes to the icosahedral capsids. Studies of JCV, BKV, and SV40 indicate that viral particles interact with PDI and ERp57 in the ER lumen to rearrange capsid proteins. In contrast, the related mouse polyomavirus (PyV) uses the PDI family member, ERp29, presumably for a similar function. The altered particles then appear to engage different retrotranslocons (dependent on either Derlin-1 or Derlin-2) to induce retrotranslocation to the cytosol, where the reduced calcium environment produces further capsid rearrangements. These particles then bind to the nuclear pore where uncoating occurs to allow passage of viral DNA into the nucleus. This figure is adapted from Neu etal. (2009). there are cell-type and virus-specific differences and that direct ER to nuclear transport may occur (Bennett et al., 2013). Low levels of calcium in the cytosol lead to further capsid destabilization and exposure of the nuclear localization signals on capsid proteins. The partially uncoated capsid then transits through the nuclear pores for initiation of viral DNA replication (Neu et al., 2009).

The preceding experiments indicate that ERAD is used by viruses to allow trafficking events that promote replication. MMTV Rem trafficking through the ER allows access to signal peptidase and cleavage of Rem precursor into functional $\mathrm{N}$ - and C-terminal proteins. In contrast, the polyomaviruses use ERAD to partially uncoat virions on their path to the nucleus. Importantly, both types of viruses avoid proteasomal degradation during ERAD, although the mechanisms remain unclear.

\section{VIRUSES AND ERAD TUNING}

ERAD may be regulated or "tuned" through the rapid turnover of specific components through the proteasomes or autophagosomes/vesicular trafficking to lysosomes (Merulla et al., 2013). Normal secretory vesicles released from the ER are $60-70 \mathrm{~nm}$ in diameter and have coatamer proteins, such as COPII, whereas the ER-derived tuning vesicles (EDEMosomes) lack coatamers and are
200-800 nm in diameter (Bernasconi et al., 2012b). Tuning vesicles contain SEL1L, EDEM1, and OS-9, which are transmembrane or luminal proteins involved in ERAD (Figure 1; Olzmann et al., 2013). EDEMosomes are believed to reduce ERAD by disposal in acidic organelles (Bernasconi et al., 2012b), favoring the correct folding of polypeptides (Calì et al., 2008). The coronaviruses are known to take advantage of ERAD tuning (Reggiori et al., 2010).

Many plus-stranded RNA-containing viruses manipulate cellular membranes to further RNA replication (Paul and Bartenschlager, 2013). These membrane structures have been divided into invaginated vesicle/spherule type and double-membrane vesicle (DMV) type (two lipid bilayers). Such vesicles allow viruses to concentrate their replication components, to separate distinct viral processes (e.g., translation, transcription, and replication), and to avoid immune detection (Paul and Bartenschlager, 2013). Severe acute respiratory syndrome coronavirus (SARS-CoV) and mouse hepatitis virus (MHV) induce DMVs for targeting their replication and transcription (Reggiori et al., 2010). The DMVs originate from ER membranes and contain the non-structural transmembrane proteins nsp3 and nsp4 and viral double-stranded RNA (Stertz et al., 2007; Reggiori et al., 2010). Nevertheless, DMVs lack markers typical of the ERGIC or the Golgi (Oostra et al., 2007). 
Recent experiments indicate that DMVs are coated with microtubule-associated protein light chain 3 [LC3; Atg8 in yeast (Reggiori et al., 2010)], which is a ubiquitin-like modifier (van der Veen and Ploegh, 2012). LC3 can exist in a lipidated form (covalent linkage to phosphatidylethanolamine; also known as LC3-II) or a predominantly cytosolic non-lipidated form (LC3-I). LC3-II is believed to be involved in fusion of autophagosomes to lysosomes (van der Veen and Ploegh, 2012), but coronavirus DMVs display the non-lipidated LC3-I (Reggiori et al., 2010). These ubiquitinlike modifiers recognize specific receptors that target associated vesicles to particular cellular locations (van der Veen and Ploegh, 2012). The coronaviruses appear to be redirecting vesicles destined for autophagosomes to sequestered locations in the cytosol where replication will occur.

The autophagy machinery is not required for coronavirus replication, and no colocalization of viral non-structural proteins was observed with LC3-II-coated autophagosomes (Reggiori et al., 2010). Coronavirus-induced DMVs and EDEMosomes both are coated with the non-lipidated LC3-I protein (Calì et al., 2008; Reggiori et al., 2010), which is not covalently attached to membranes like LC3-II (Kabeya et al., 2000). Induction of autophagy in coronavirus-infected cells with rapamycin decreased the levels of EDEM1 and coronavirus (Reggiori et al., 2010). The viruscontaining DMVs had both EDEM1 and OS-9, but not other ERAD-associated chaperones, and virus infection interfered with ERAD tuning by hijacking the EDEMosomes. Nevertheless, LC3-I, but not EDEM1 and OS-9, is necessary for coronavirus infection, and the hijacked EDEMosome cargo is not degraded by proteases in the endosomes/lysosomes (Reggiori et al., 2010). Further, the ERAD transmembrane adapter protein, SEL1L, is needed for DMV formation, capturing the ER-resident EDEM1 and OS9 proteins (and possibly XTP3-B and EDEM3), while using its proline-rich cytosolic domain to bind to LC3-I. As expected, SEL1L knockdown impairs coronavirus replication (Bernasconi et al., 2012a).

The organizationally similar arterioviruses (classified with coronaviruses, toroviruses, and roniviruses into the order Nidovirales; Gorbalenya etal., 2006) subvert EDEMosome trafficking for their replication, although the size of the vesicles is smaller (Monastyrska et al., 2013). The mechanism for altering EDEM1containing vesicular trafficking is unclear, but likely involves expression of viral non-structural proteins that span the ERderived membranes (Monastyrska et al., 2013), perhaps through their interaction with SEL1L. These experiments indicate that viruses hijack EDEMosomes to sequester their double-stranded RNA from cytosolic sensors that will trigger interferon production and innate immunity (Zinzula and Tramontano, 2013). Other components of the ERAD system, particularly chaperone proteins, also participate in the replication and transmission of both plant and mammalian viruses (Verchot, 2014).

\section{CONCLUSION}

The ERAD system is a complex and highly regulated process controlling the disposal of misfolded or misassembled proteins that are directed to the ER for translation. Deregulation of this process results in pathogenic conditions, including infectious diseases. Viruses exploit ERAD to decrease overall viral levels and allow establishment of chronic infections by minimizing antigen presentation to the immune system. Trafficking of specific viral proteins or entire virion particles may involve ERAD for refolding or processing in the unique ER environment. Alternatively, viruses can use ERAD-associated components to form isolated lipid vesicles for replication and shelter from immune detection. Virus-mediated subversion of ERAD can lead to degradation of molecules that are involved in innate or adaptive immunity. Continued studies of viruses are certain to provide additional insights into both the ERAD process and the components that regulate it. Further experiments may identify targets for viral therapeutics.

\section{ACKNOWLEDGMENTS}

We thank Dr. Jon Huibregtse for helpful comments and suggestions on the manuscript and Marianna Grenadier for the figures. This work was supported by NIH grants R01CA167053 and R21AI105710.

\section{REFERENCES}

Abujarour, R. J., Dalal, S., Hanson, P. I., and Draper, R. K. (2005). p97 is in a complex with cholera toxin and influences the transport of cholera toxin and related toxins to the cytoplasm. J. Biol. Chem. 280, 15865-15871. doi: 10.1074/jbc.M406316200

Aebi, M., Bernasconi, R., Clerc, S., and Molinari, M. (2010). N-glycan structures: recognition and processing in the ER. Trends Biochem. Sci. 35, 74-82. doi: 10.1016/j.tibs.2009.10.001

Alexandru, G., Graumann, J., Smith, G. T., Kolawa, N. J., Fang, R., and Deshaies, R. J. (2008). UBXD7 binds multiple ubiquitin ligases and implicates p97 in HIF1alpha turnover. Cell 134, 804-816. doi: 10.1016/j.cell.2008.06.048

Allen, S., Naim, H. Y., and Bulleid, N. J. (1995). Intracellular folding of tissue-type plasminogen activator. Effects of disulfide bond formation on N-linked glycosylation and secretion. J. Biol. Chem. 270, 4797-4804. doi: 10.1074/jbc.270.9.4797

Argañaraz, E. R., Schindler, M., Kirchhoff, F., Cortes, M. J., and Lama, J. (2003). Enhanced CD4 down-modulation by late stage HIV-1 nef alleles is associated with increased Env incorporation and viral replication. J. Biol. Chem. 278, 3391233919. doi: 10.1074/jbc.M303679200

Arroyo, J., Hutzler, J., Bermejo, C., Ragni, E., García-Cantalejo, J., Botías, P., et al. (2011). Functional and genomic analyses of blocked protein O-mannosylation in baker's yeast. Mol. Microbiol. 79, 1529-1546. doi: 10.1111/j.13652958.2011.07537.x

Ast, T., Cohen, G., and Schuldiner, M. (2013). A network of cytosolic factors targets SRP-independent proteins to the endoplasmic reticulum. Cell 152, 1134-1145. doi: 10.1016/j.cell.2013.02.003

Auclair, S. M., Bhanu, M. K., and Kendall, D. A. (2012). Signal peptidase I: cleaving the way to mature proteins. Protein Sci. 21, 13-25. doi: 10.1002/pro.757

Barel, M. T., Pizzato, N., van Leeuwen, D., Bouteiller, P. L., Wiertz, E. J. H. J., and Lenfant, F. (2003). Amino acid composition of alpha1/alpha2 domains and cytoplasmic tail of MHC class I molecules determine their susceptibility to human cytomegalovirus US11-mediated down-regulation. Eur. J. Immunol. 33, 17071716. doi: 10.1002/eji.200323912

Barouch, D. H., and Harrison, S. C. (1994). Interactions among the major and minor coat proteins of polyomavirus. J. Virol. 68, 3982-3989.

Bass, R., and Edwards, D. R. (2010). ADAMs and protein disulfide isomerase: the key to regulated cell-surface protein ectodomain shedding? Biochem. J. 428, e3-e5. doi: 10.1042/BJ20100568

Bays, N. W., and Hampton, R. Y. (2002). Cdc48-Ufd1-Npl4: stuck in the middle with Ub. Curr. Biol. 12, R366-R371. doi: 10.1016/S0960-9822(02)00862-X

Ben-Dor, S., Esterman, N., Rubin, E., and Sharon, N. (2004). Biases and complex patterns in the residues flanking protein N-glycosylation sites. Glycobiology 14, 95-101. doi: 10.1093/glycob/cwh004

Benham, A. M. (2012). The protein disulfide isomerase family: key players in health and disease. Antioxid. Redox Signal. 16, 781-789. doi: 10.1089/ars.2011.4439

Bennett, S. M., Jiang, M., and Imperiale, M. J. (2013). Role of cell-type-specific endoplasmic reticulum-associated degradation in polyomavirus trafficking. $J$. Virol. 87, 8843-8852. doi: 10.1128/JVI.00664-13 
Bernardi, K. M., Forster, M. L., Lencer, W. I., and Tsai, B. (2008). Derlin-1 facilitates the retro-translocation of cholera toxin. Mol. Biol. Cell 19, 877-884. doi: 10.1091/mbc.E07-08-0755

Bernardi, K. M., Williams, J. M., Kikkert, M., van Voorden, S., Wiertz, E. J., Ye, Y., et al. (2010). The E3 ubiquitin ligases Hrd1 and gp78 bind to and promote cholera toxin retro-translocation. Mol. Biol. Cell 21, 140-151. doi: 10.1091/mbc.E0907-0586

Bernasconi, R., Galli, C., Calanca, V., Nakajima, T., and Molinari, M. (2010a). Stringent requirement for HRD1, SEL1L, and OS-9/XTP3-B for disposal of ERAD-LS substrates. J. Cell Biol. 188, 223-235. doi: 10.1083/jcb.200910042

Bernasconi, R., Soldà, T., Galli, C., Pertel, T., Luban, J., and Molinari, M. (2010b). Cyclosporine A-sensitive, cyclophilin B-dependent endoplasmic reticulumassociated degradation. PLOS ONE 5:e13008. doi: 10.1371/journal.pone.0013008

Bernasconi, R., Galli, C., Noack, J., Bianchi, S., de Haan, C. A. M., Reggiori, F., et al. (2012a). Role of the SEL1L:LC3-I complex as an ERAD tuning receptor in the mammalian ER. Mol. Cell 46, 809-819. doi: 10.1016/j.molcel.2012.04.017

Bernasconi, R., Noack, J., and Molinari, M. (2012b). Unconventional roles of nonlipidated LC3 in ERAD tuning and coronavirus infection. Autophagy 8, 1534-1536 doi: 10.4161/auto.21229

Bernasconi, R., Pertel, T., Luban, J., and Molinari, M. (2008). A dual task for the Xbpl-responsive OS- 9 variants in the mammalian endoplasmic reticulum: inhibiting secretion of misfolded protein conformers and enhancing their disposal. J. Biol. Chem. 283, 16446-16454. doi: 10.1074/jbc.M802272200

Bhattacharyya, S., Yu, H., Mim, C., and Matouschek, A. (2014). Regulated protein turnover: snapshots of the proteasome in action. Nat. Rev. Mol. Cell Biol. 15, 122-133. doi: 10.1038/nrm3741

Boname, J. M., and Stevenson, P. G. (2001). MHC class I ubiquitination by a viral PHD/LAP finger protein. Immunity 15, 627-636. doi: 10.1016/S10747613(01)00213-8

Braestrup, C., and Squires, R. F. (1977). Specific benzodiazepine receptors in rat brain characterized by high-affinity $(3 \mathrm{H})$ diazepam binding. Proc. Natl. Acad. Sci. U.S.A. 74, 3805-3809. doi: 10.1073/pnas.74.9.3805

Bray, M., Prasad, S., Dubay, J. W., Hunter, E., Jeang, K. T., Rekosh, D., et al. (1994). A small element from the Mason-Pfizer monkey virus genome makes human immunodeficiency virus type 1 expression and replication Rev-independent. Proc. Natl. Acad. Sci. U.S.A. 91, 1256-1260. doi: 10.1073/pnas.91.4.1256

Breitling, J., and Aebi, M. (2013). N-linked protein glycosylation in the endoplasmic reticulum. Cold Spring Harb. Perspect. Biol. 5:a013359. doi: 10.1101/cshperspect.a013359

Brodsky, J. L. (2012). Cleaning up: ER-associated degradation to the rescue. Cell 151, 1163-1167. doi: 10.1016/j.cell.2012.11.012

Brodsky, J. L., and Skach, W. R. (2011). Protein folding and quality control in the endoplasmic reticulum: recent lessons from yeast and mammalian cell systems. Curr. Opin. Cell Biol. 23, 464-475. doi: 10.1016/j.ceb.2011.05.004

Brodsky, J. L., and Wojcikiewicz, R. J. H. (2009). Substrate-specific mediators of ER associated degradation (ERAD). Curr. Opin. Cell Biol. 21, 516-521. doi 10.1016/j.ceb.2009.04.006

Byun, H., Halani, N., Gou, Y., Nash, A. K., Lozano, M. M., and Dudley, J. P. (2012). Requirements for mouse mammary tumor virus Rem signal peptide processing and function. J. Virol. 86, 214-225. doi: 10.1128/JVI.06197-11

Byun, H., Halani, N., Mertz, J. A., Ali, A. F., Lozano, M. M., and Dudley, J. P. (2010). Retroviral Rem protein requires processing by signal peptidase and retrotranslocation for nuclear function. Proc. Natl. Acad. Sci. U.S.A. 107, 12287-12292. doi: 10.1073/pnas.1004303107

Calì, T., Galli, C., Olivari, S., and Molinari, M. (2008). Segregation and rapid turnover of EDEM1 by an autophagy-like mechanism modulates standard ERAD and folding activities. Biochem. Biophys. Res. Commun. 371, 405-410. doi: 10.1016/j.bbrc.2008.04.098

Carvalho, P., Stanley, A. M., and Rapoport, T. A. (2010). Retrotranslocation of a misfolded luminal ER protein by the ubiquitin-ligase Hrd1p. Cell 143, 579-591. doi: 10.1016/j.cell.2010.10.028

Chavan, M., and Lennarz, W. (2006). The molecular basis of coupling of translocation and N-glycosylation. Trends Biochem. Sci. 31, 17-20. doi: 10.1016/j.tibs.2005.11.010

Chevalier, M. S., and Johnson, D. C. (2003). Human cytomegalovirus US3 chimeras containing US2 cytosolic residues acquire major histocompatibility class I and II protein degradation properties. J. Virol. 77, 4731-4738. doi: 10.1128/JVI.77.8.4731-4738.2003
Cho, S., Kim, B. Y., Ahn, K., and Jun, Y. (2013a). The C-terminal amino acid of the MHC-I heavy chain is critical for binding to Derlin-1 in human cytomegalovirus US11-induced MHC-I degradation. PLOS ONE 8:e72356. doi: 10.1371/journal.pone.0072356

Cho, S., Lee, M., and Jun, Y. (2013b). Forced interaction of cell surface proteins with Derlin-1 in the endoplasmic reticulum is sufficient to induce their dislocation into the cytosol for degradation. Biochem. Biophys. Res. Commun. 430, 787-792. doi: 10.1016/j.bbrc.2012.11.068

Christianson, J. C., Olzmann, J. A., Shaler, T. A., Sowa, M. E., Bennett, E. J., Richter, C. M., et al. (2012). Defining human ERAD networks through an integrative mapping strategy. Nat. Cell Biol. 14, 93-105. doi: 10.1038/ncb2383

Christianson, J. C., Shaler, T. A., Tyler, R. E., and Kopito, R. R. (2008). OS-9 and GRP94 deliver mutant alphal-antitrypsin to the Hrd1-SEL1L ubiquitin ligase complex for ERAD. Nat. Cell Biol. 10, 272-282. doi: 10.1038/ncb1689

Costantini, L. M., Subach, O. M., Jaureguiberry-bravo, M., Verkhusha, V. V., and Snapp, E. L. (2013). Cysteineless non-glycosylated monomeric blue fluorescent protein, secBFP2, for studies in the eukaryotic secretory pathway. Biochem. Biophys. Res. Commun. 430, 1114-1119. doi: 10.1016/j.bbrc.2012.12.028

Coyne, C. B., Bozym, R., Morosky, S. A., Hanna, S. L., Mukherjee, A., Tudor, M., et al. (2011). Comparative RNAi screening reveals host factors involved in enterovirus infection of polarized endothelial monolayers. Cell Host Microbe 9, 70-82. doi: 10.1016/j.chom.2011.01.001

Cullen, B. R. (2003). Nuclear mRNA export: insights from virology. Trends Biochem. Sci. 28, 419-424. doi: 10.1016/S0968-0004(03)00142-7

Daly, T. J., Cook, K. S., Gray, G. S., Maione, T. E., and Rusche, J. R. (1989). Specific binding of HIV-1 recombinant Rev protein to the Rev-responsive element in vitro. Nature 342, 816-819. doi: 10.1038/342816a0

Denic, V. (2012). A portrait of the GET pathway as a surprisingly complicated young man. Trends Biochem. Sci. 37, 411-417. doi: 10.1016/j.tibs.2012.07.004

Denic, V., Quan, E. M., and Weissman, J. S. (2006). A luminal surveillance complex that selects misfolded glycoproteins for ER-associated degradation. Cell 126, 349359. doi: 10.1016/j.cell.2006.05.045

Dultz, E., Hildenbeutel, M., Martoglio, B., Hochman, J., Dobberstein, B., and Kapp, $\mathrm{K}$. (2008). The signal peptide of the mouse mammary tumor virus Rem protein is released from the endoplasmic reticulum membrane and accumulates in nucleoli. J. Biol. Chem. 283, 9966-9976. doi: 10.1074/jbc.M705712200

Düsterhöft, S., Jung, S., Hung, C.-W., Tholey, A., Sönnichsen, F. D., Grötzinger, J., et al. (2013). Membrane-proximal domain of a disintegrin and metalloprotease17 represents the putative molecular switch of its shedding activity operated by protein-disulfide isomerase. J. Am. Chem. Soc. 135, 5776-5781. doi: 10.1021/ja400340u

Eash, S., and Atwood, W. J. (2005). Involvement of cytoskeletal components in BK virus infectious entry. J. Virol. 79, 11734-11741. doi: 10.1128/JVI.79.18.1173411741.2005

Ecker, M., Mrsa, V., Hagen, I., Deutzmann, R., Strahl, S., and Tanner, W. (2003). $\mathrm{O}$-mannosylation precedes and potentially controls the N-glycosylation of a yeast cell wall glycoprotein. EMBO Rep. 4, 628-632. doi: 10.1038/sj.embor. embor864

El Khouri, E., Le Pavec, G., Toledano, M. B., and Delaunay-Moisan, A. (2013). RNF185 is a novel E3 ligase of endoplasmic reticulum-associated degradation (ERAD) that targets cystic fibrosis transmembrane conductance regulator (CFTR). J. Biol. Chem. 288, 31177-31191. doi: 10.1074/jbc.M113.470500

Ernst, R., Mueller, B., Ploegh, H. L., and Schlieker, C. (2009). The otubain YOD1 is a deubiquitinating enzyme that associates with $\mathrm{p} 97$ to facilitate protein dislocation from the ER. Mol. Cell 36, 28-38. doi: 10.1016/j.molcel.2009.09.016

Erzberger, J. P., and Berger, J. M. (2006). Evolutionary relationships and structural mechanisms of AAA+ proteins. Annu. Rev. Biophys. Biomol. Struct. 35, 93-114. doi: 10.1146/annurev.biophys.35.040405.101933

Fairbank, M., St-Pierre, P., and Nabi, I. R. (2009). The complex biology of autocrine motility factor/phosphoglucose isomerase (AMF/PGI) and its receptor, the gp78/AMFR E3 ubiquitin ligase. Mol. Biosyst. 5, 793-801. doi: 10.1039/b820820b

Falk, M. M., and Gilula, N. B. (1998). Connexin membrane protein biosynthesis is influenced by polypeptide positioning within the translocon and signal peptidase access. J. Biol. Chem. 273, 7856-7864. doi: 10.1074/jbc.273.14.7856

Fang, S., Ferrone, M., Yang, C., Jensen, J. P., Tiwari, S., and Weissman, A. M. (2001). The tumor autocrine motility factor receptor, gp78, is a ubiquitin protein ligase implicated in degradation from the endoplasmic reticulum. Proc. Natl. Acad. Sci. U.S.A. 98, 14422-14427. doi: 10.1073/pnas. 251401598 
Farquhar, R., Honey, N., Murant, S. J., Bossier, P., Schultz, L., Montgomery, D., et al. (1991). Protein disulfide isomerase is essential for viability in Saccharomyces cerevisiae. Gene 108, 81-89. doi: 10.1016/0378-1119(91)90490-3

Fleig, L., Bergbold, N., Sahasrabudhe, P., Geiger, B., Kaltak, L., and Lemberg, M. K. (2012). Ubiquitin-dependent intramembrane rhomboid protease promotes ERAD of membrane proteins. Mol. Cell 47, 558-569. doi: 10.1016/j.molcel. 2012.06.008

Flierman, D., Coleman, C. S., Pickart, C. M., Rapoport, T. A., and Chau, V. (2006) E2-25K mediates US11-triggered retro-translocation of MHC class I heavy chains in a permeabilized cell system. Proc. Natl. Acad. Sci. U.S.A. 103, 11589-11594. doi: 10.1073/pnas.0605215103

Forster, M. L., Sivick, K., Park, Y.-N., Arvan, P., Lencer, W. I., and Tsai, B. (2006). Protein disulfide isomerase-like proteins play opposing roles during retrotranslocation. J. Cell Biol. 173, 853-859. doi: 10.1083/jcb.2006 02046

Franz, A., Ackermann, L., and Hoppe, T. (2014). Create and preserve: proteostasis in development and aging is governed by Cdc48/p97/VCP. Biochim. Biophys. Acto 1843, 205-215. doi: 10.1016/j.bbamcr.2013.03.031

Frenkel, Z., Shenkman, M., Kondratyev, M., and Lederkremer, G. Z. (2004). Separate roles and different routing of calnexin and ERp57 in endoplasmic reticulum quality control revealed by interactions with asialoglycoprotein receptor chains. Mol. Biol. Cell 15, 2133-2142. doi: 10.1091/mbc.E03-12-0899

Fu, M., St-Pierre, P., Shankar, J., Wang, P. T. C., Joshi, B., and Nabi, I. R. (2013). Regulation of mitophagy by the Gp78 E3 ubiquitin ligase. Mol. Biol. Cell 24, 1153-1162. doi: 10.1091/mbc.E12-08-0607

Fujinaga, Y., Wolf, A. A., Rodighiero, C., Wheeler, H., Tsai, B., Allen, L., et al (2003). Gangliosides that associate with lipid rafts mediate transport of cholera and related toxins from the plasma membrane to endoplasmic reticulm. Mol Biol. Cell 14, 4783-4793. doi: 10.1091/mbc.E03-06-0354

Geiger, R., Andritschke, D., Friebe, S., Herzog, F., Luisoni, S., Heger, T., et al. (2011). BAP31 and BiP are essential for dislocation of SV40 from the endoplasmic reticulum to the cytosol. Nat. Cell Biol. 13, 1305-1314. doi: 10.1038/ ncb2339

Gogala, M., Becker, T., Beatrix, B., Armache, J.-P., Barrio-Garcia, C., Berninghausen, O., et al. (2014). Structures of the Sec61 complex engaged in nascent peptide translocation or membrane insertion. Nature 506, 107-110. doi: 10.1038 /nature 12950

Gonzalez, D. S., Karaveg, K., Vandersall-Nairn, A. S., Lal, A., and Moremen, K. W. (1999). Identification, expression, and characterization of a cDNA encoding human endoplasmic reticulum mannosidase I, the enzyme that catalyzes the first mannose trimming step in mammalian Asn-linked oligosaccharide biosynthesis. J. Biol. Chem. 274, 21375-21386. doi: 10.1074/jbc.274.30.21375

Gorbalenya, A. E., Enjuanes, L., Ziebuhr, J., and Snijder, E. J. (2006). Nidovirales: evolving the largest RNA virus genome. Virus Res. 117, 17-37. doi: 10.1016/j.virusres.2006.01.017

Greenblatt, E. J., Olzmann, J. A., and Kopito, R. R. (2011). Derlin-1 is a rhomboid pseudoprotease required for the dislocation of mutant $\alpha-1$ antitrypsin from the endoplasmic reticulum. Nat. Struct. Mol. Biol. 18, 1147-1152. doi: 10.1038/ nsmb. 2111

Groll, M., Bajorek, M., Köhler, A., Moroder, L., Rubin, D. M., Huber, R., et al. (2000). A gated channel into the proteasome core particle. Nat. Struct. Biol. 7, 1062-1067. doi: 10.1038/80992

Grubb, S., Guo, L., Fisher, E. A., and Brodsky, J. L. (2012). Protein disulfide isomerases contribute differentially to the endoplasmic reticulum-associated degradation of apolipoprotein B and other substrates. Mol. Biol. Cell 23, 520-532. doi: 10.1091/mbc.E11-08-0704

Grüter, P., Tabernero, C., von Kobbe, C., Schmitt, C., Saavedra, C., Bachi, A., et al. (1998). TAP, the human homolog of Mex67p, mediates CTE-dependent RNA export from the nucleus. Mol. Cell 1, 649-659. doi: 10.1016/S1097-2765(00) 80065-9

Guerriero, C. J., and Brodsky, J. L. (2012). The delicate balance between secreted protein folding and endoplasmic reticulum-associated degradation in human physiology. Physiol. Rev. 92, 537-576. doi: 10.1152/physrev.00027.2011

Hampton, R. Y., and Sommer, T. (2012). Finding the will and the way of ERAD substrate retrotranslocation. Curr. Opin. Cell Biol. 24, 460-466. doi: 10.1016/j.ceb. 2012.05.010

Hanly, S. M., Rimsky, L. T., Malim, M. H., Kim, J. H., Hauber, J., Duc Dodon, M., etal. (1989). Comparative analysis of the HTLV-I Rex and HIV-1 Rev trans-regulatory proteins and their RNA response elements. Genes Dev. 3, 1534-1544. doi: 10.1101/gad.3.10.1534

Hazes, B., and Read, R. J. (1997). Accumulating evidence suggests that several AB-toxins subvert the endoplasmic reticulum-associated protein degradation pathway to enter target cells. Biochemistry 36, 11051-11054. doi: 10.1021/bi971383p

Head, B. P., Patel, H. H., and Insel, P. A. (2014). Interaction of membrane/lipid rafts with the cytoskeleton: impact on signaling and function: membrane/lipid rafts, mediators of cytoskeletal arrangement and cell signaling. Biochim. Biophys. Acta 1838, 532-545. doi: 10.1016/j.bbamem.2013.07.018

Hebert, D. N., and Molinari, M. (2007). In and out of the ER: protein folding, quality control, degradation, and related human diseases. Physiol. Rev. 87, 1377-1408. doi: 10.1152/physrev.00050.2006

Herr, R. A., Harris, J., Fang, S., Wang, X., and Hansen, T. H. (2009). Role of the RING-CH domain of viral ligase $\mathrm{mK} 3$ in ubiquitination of non-lysine and lysine MHC I residues. Traffic 10, 1301-1317. doi: 10.1111/j.1600-0854.2009.00946.x

Hirao, K., Natsuka, Y., Tamura, T., Wada, I., Morito, D., Natsuka, S., et al. (2006). EDEM3, a soluble EDEM homolog, enhances glycoprotein endoplasmic reticulum-associated degradation and mannose trimming. J. Biol. Chem. 281, 9650-9658. doi: 10.1074/jbc.M512191200

Hirsch, C., Blom, D., and Ploegh, H. L. (2003). A role for N-glycanase in the cytosolic turnover of glycoproteins. EMBO J. 22, 1036-1046. doi: 10.1093/emboj/cdg107

Hoseki, J., Ushioda, R., and Nagata, K. (2010). Mechanism and components of endoplasmic reticulum-associated degradation. J. Biochem. 147, 19-25. doi: $10.1093 / \mathrm{jb} / \mathrm{mvp} 194$

Hosokawa, N., Wada, I., Nagasawa, K., Moriyama, T., Okawa, K., and Nagata, K. (2008). Human XTP3-B forms an endoplasmic reticulum quality control scaffold with the HRD1-SEL1L ubiquitin ligase complex and BiP. J. Biol. Chem. 283, 20914-20924. doi: 10.1074/jbc.M709336200

Hosokawa, N., You, Z., Tremblay, L. O., Nagata, K., and Herscovics, A. (2007). Stimulation of ERAD of misfolded null Hong Kong alphal-antitrypsin by Golgi alpha1,2-mannosidases. Biochem. Biophys. Res. Commun. 362, 626-632. doi: 10.1016/j.bbrc.2007.08.057

Howell, D. N., Andreotti, P. E., Dawson, J. R., and Cresswell, P. (1985). Natural killing target antigens as inducers of interferon: studies with an immunoselected, natural killing-resistant human T lymphoblastoid cell line. J. Immunol. 134, 971-976.

Hoxie, J. A., Alpers, J. D., Rackowski, J. L., Huebner, K., Haggarty, B. S., Cedarbaum, A. J., et al. (1986). Alterations in T4 (CD4) protein and mRNA synthesis in cells infected with HIV. Science 234, 1123-1127. doi: 10.1126/science.3095925

Hrizo, S. L., Gusarova, V., Habiel, D. M., Goeckeler, J. L., Fisher, E. A., and Brodsky, J. L. (2007). The Hsp110 molecular chaperone stabilizes apolipoprotein B from endoplasmic reticulum-associated degradation (ERAD). J. Biol. Chem. 282, 32665-32675. doi: 10.1074/jbc.M705216200

Indik, S., Günzburg, W. H., Salmons, B., and Rouault, F. (2005). A novel, mouse mammary tumor virus encoded protein with Rev-like properties. Virology 337, 1-6. doi: 10.1016/j.virol.2005.03.040

Ishikawa, J., Kaisho, T., Tomizawa, H., Lee, B. O., Kobune, Y., Inazawa, J., et al. (1995). Molecular cloning and chromosomal mapping of a bone marrow stromal cell surface gene, BST2, that may be involved in pre-B-cell growth. Genomics 26, 527-534. doi: 10.1016/0888-7543(95)80171-H

Jacobs, J. L., and Coyne, C. B. (2013). Mechanisms of MAVS regulation at the mitochondrial membrane. J. Mol. Biol. 425, 5009-5019. doi: 10.1016/j.jmb. 2013.10.007

Jacobs, J. L., Zhu, J., Sarkar, S. N., and Coyne, C. B. (2014). Regulation of mitochondrial antiviral signaling (MAVS) expression and signaling by the mitochondria-associated endoplasmic reticulum membrane (MAM) protein Gp78. J. Biol. Chem. 289, 1604-1616. doi: 10.1074/jbc.M113.520254

Jentsch, S., and Rumpf, S. (2007). Cdc48 (p97): a "molecular gearbox" in the ubiquitin pathway? Trends Biochem. Sci. 32, 6-11. doi: 10.1016/j.tibs.2006. 11.005

Jiang, M., Abend, J. R., Tsai, B., and Imperiale, M. J. (2009). Early events during BK virus entry and disassembly. J. Virol. 83, 1350-1358. doi: 10.1128/JVI.02169-08

Johnson, A. E., and Haigh, N. G. (2000). The ER translocon and retrotranslocation: is the shift into reverse manual or automatic? Cell 102, 709-712. doi: 10.1016/S00928674(00)00059-3

Johnson, N., Powis, K., and High, S. (2013). Post-translational translocation into the endoplasmic reticulum. Biochim. Biophys. Acta 1833, 2403-2409. doi: 10.1016/j.bbamcr.2012.12.008 
Johnson, N., Vilardi, F., Lang, S., Leznicki, P., Zimmermann, R., and High, S. (2012). TRC40 can deliver short secretory proteins to the Sec61 translocon. J. Cell Sci. 125, 3612-3620. doi: 10.1242/jcs. 102608

Kabeya, Y., Mizushima, N., Ueno, T., Yamamoto, A., Kirisako, T., Noda, T., et al. (2000). LC3, a mammalian homologue of yeast Apg8p, is localized in autophagosome membranes after processing. EMBO J. 19, 5720-5728. doi: $10.1093 / \mathrm{emboj} / 19.21 .5720$

Kamhi-Nesher, S., Shenkman, M., Tolchinsky, S., Fromm, S. V., Ehrlich, R., and Lederkremer, G. Z. (2001). A novel quality control compartment derived from the endoplasmic reticulum. Mol. Biol. Cell 12, 1711-1723. doi: 10.1091/mbc.12.6.1711

Kawai, T., Takahashi, K., Sato, S., Coban, C., Kumar, H., Kato, H., et al. (2005). IPS1 , an adaptor triggering RIG-I- and Mda5-mediated type I interferon induction. Nat. Immunol. 6, 981-988. doi: 10.1038/ni1243

Kikkert, M., Doolman, R., Dai, M., Avner, R., Hassink, G., van Voorden, S. et al. (2004). Human HRD1 is an E3 ubiquitin ligase involved in degradation of proteins from the endoplasmic reticulum. J. Biol. Chem. 279, 3525-3534. doi: 10.1074/jbc.M307453200

Kiser, G. L., Gentzsch, M., Kloser, A. K., Balzi, E., Wolf, D. H., Goffeau, A., et al (2001). Expression and degradation of the cystic fibrosis transmembrane conductance regulator in Saccharomyces cerevisiae. Arch. Biochem. Biophys. 390, 195-205. doi: 10.1006/abbi.2001.2385

Komander, D., Reyes-Turcu, F., Licchesi, J. D. F., Odenwaelder, P., Wilkinson, K. D., and Barford, D. (2009). Molecular discrimination of structurally equivalen Lys 63-linked and linear polyubiquitin chains. EMBO Rep. 10, 466-473. doi: 10.1038/embor.2009.55

Kothe, M., Ye, Y., Wagner, J. S., De Luca, H. E., Kern, E., Rapoport, T. A., et al. (2005). Role of p97 AAA-ATPase in the retrotranslocation of the cholera toxin Al chain, a non-ubiquitinated substrate. J. Biol. Chem. 280, 28127-28132. doi: 10.1074/jbc.M503138200

Kreft, S. G., and Hochstrasser, M. (2011). An unusual transmembrane helix in the endoplasmic reticulum ubiquitin ligase Doa10 modulates degradation of its cognate E2 enzyme. J. Biol. Chem. 286, 20163-20174. doi: 10.1074/jbc.M110. 196360

Kupzig, S., Korolchuk, V., Rollason, R., Sugden, A., Wilde, A., and Banting, G. (2003) Bst-2/HM1.24 is a raft-associated apical membrane protein with an unusual topology. Traffic 4, 694-709. doi: 10.1034/j.1600-0854.2003.00129.x

Lanzavecchia, A., Roosnek, E., Gregory, T., Berman, P., and Abrignani, S. (1988). $\mathrm{T}$ cells can present antigens such as HIV gp120 targeted to their own surface molecules. Nature 334, 530-532. doi: 10.1038/334530a0

Lazar, C., Macovei, A., Petrescu, S., and Branza-Nichita, N. (2012). Activation of ERAD pathway by human HBV modulates viral and subviral particle production. PLoS ONE 7:e34169. doi: 10.1371/journal.pone.0034169

Lederkremer, G. Z., and Glickman, M. H. (2005). A window of opportunity: timing protein degradation by trimming of sugars and ubiquitins. Trends Biochem. Sci. 30, 297-303. doi: 10.1016/j.tibs.2005.04.010

Li, B., Gao, B., Ye, L., Han, X., Wang, W., Kong, L., et al. (2007). Hepatitis B virus $\mathrm{X}$ protein $(\mathrm{HBx})$ activates ATF6 and IRE1-XBP1 pathways of unfolded protein response. Virus Res. 124, 44-49. doi: 10.1016/j.virusres.2006.09.011

Li, G., Zhao, G., Zhou, X., Schindelin, H., and Lennarz, W. J. (2006). The AAA ATPase p97 links peptide $\mathrm{N}$-glycanase to the endoplasmic reticulum-associated E3 ligase autocrine motility factor receptor. Proc. Natl. Acad. Sci. U.S.A. 103, 8348-8353. doi: 10.1073/pnas.0602747103

Li, J., Liu, Y., Wang, Z., Liu, K., Wang, Y., Liu, J., et al. (2011). Subversion of cellular autophagy machinery by hepatitis B virus for viral envelopment. J. Virol. 85 , 6319-6333. doi: 10.1128/JVI.02627-10

Li, T.-C., Takeda, N., Kato, K., Nilsson, J., Xing, L., Haag, L., et al. (2003) Characterization of self-assembled virus-like particles of human polyomavirus BK generated by recombinant baculoviruses. Virology 311, 115-124. doi: 10.1016/S0042-6822(03)00141-7

Lilley, B. N., Gilbert, J. M., Ploegh, H. L., and Benjamin, T. L. (2006). Murine polyomavirus requires the endoplasmic reticulum protein Derlin-2 to initiate infection. J. Virol. 80, 8739-8744. doi: 10.1128/JVI.00791-06

Lilley, B. N., and Ploegh, H. L. (2004). A membrane protein required for dislocation of misfolded proteins from the ER. Nature 429, 834-840. doi: 10.1038 /nature02592

Lipson, C., Alalouf, G., Bajorek, M., Rabinovich, E., Atir-Lande, A., Glickman, M., et al. (2008). A proteasomal ATPase contributes to dislocation of endoplasmic reticulum-associated degradation (ERAD) substrates. J. Biol. Chem. 283, 71667175. doi: 10.1074/jbc.M705893200

Loibl, M., Wunderle, L., Hutzler, J., Schulz, B. L., Aebi, M., and Strahl, S. (2014). Protein O-mannosyltransferases associate with the translocon to modify translocating polypeptide chains. J. Biol. Chem. 289, 8599-8611. doi: 10.1074/jbc.M113.543116

Loureiro, J., Lilley, B. N., Spooner, E., Noriega, V., Tortorella, D., and Ploegh, H. L. (2006). Signal peptide peptidase is required for dislocation from the endoplasmic reticulum. Nature 441, 894-897. doi: 10.1038/nature04830

Määttänen, P., Gehring, K., Bergeron, J. J. M., and Thomas, D. Y. (2010). Protein quality control in the ER: the recognition of misfolded proteins. Semin. Cell Dev. Biol. 21, 500-511. doi: 10.1016/j.semcdb.2010.03.006

Magadán, J. G., Pérez-Victoria, F. J., Sougrat, R., Ye, Y., Strebel, K., and Bonifacino, J. S. (2010). Multilayered mechanism of CD4 downregulation by HIV-1 Vpu involving distinct ER retention and ERAD targeting steps. PLoS Pathog. 6:e1000869. doi: 10.1371/journal.ppat.1000869

Magnuson, B., Rainey, E. K., Benjamin, T., Baryshev, M., Mkrtchian, S., and Tsai, B. (2005). ERp29 triggers a conformational change in polyomavirus to stimulate membrane binding. Mol. Cell 20, 289-300. doi: 10.1016/j.molcel.2005.08.034

Mangeat, B., Gers-Huber, G., Lehmann, M., Zufferey, M., Luban, J., and Piguet, V. (2009). HIV-1 Vpu neutralizes the antiviral factor Tetherin/BST-2 by binding it and directing its beta-TrCP2-dependent degradation. PLoS Pathog. 5:e1000574. doi: 10.1371/journal.ppat.1000574

Margottin, F., Bour, S. P., Durand, H., Selig, L., Benichou, S., Richard, V., et al. (1998). A novel human WD protein, h-beta TrCp, that interacts with HIV-1 Vpu connects CD4 to the ER degradation pathway through an F-box motif. Mol. Cell 1, 565-574. doi: 10.1016/S1097-2765(00)80056-8

Matouschek, A., and Finley, D. (2012). Cell biology. An ancient portal to proteolysis. Science 337, 813-814. doi: 10.1126/science.1227301

Matsumura, Y., Sakai, J., and Skach, W. R. (2013). Endoplasmic reticulum protein quality control is determined by cooperative interactions between Hsp/c70 protein and the CHIP E3 ligase. J. Biol. Chem. 288, 31069-31079. doi: 10.1074/jbc.M113.479345

McClure, M. O., Sattentau, Q. J., Beverley, P. C., Hearn, J. P., Fitzgerald, A. K., Zuckerman, A. J., et al. (1987). HIV infection of primate lymphocytes and conservation of the CD4 receptor. Nature 330, 487-489. doi: 10.1038/330487a0

Mertz, J. A., Chadee, A. B., Byun, H., Russell, R., and Dudley, J. P. (2009a). Mapping of the functional boundaries and secondary structure of the mouse mammary tumor virus Rem-responsive element. J. Biol. Chem. 284, 25642-25652. doi: 10.1074/jbc.M109.012476

Mertz, J. A., Lozano, M. M., and Dudley, J. P. (2009b). Rev and Rex proteins of human complex retroviruses function with the MMTV Rem-responsive element. Retrovirology 6:10. doi: 10.1186/1742-4690-6-10

Mertz, J. A., Simper, M. S., Lozano, M. M., Payne, S. M., and Dudley, J. P. (2005). Mouse mammary tumor virus encodes a self-regulatory RNA export protein and is a complex retrovirus. J. Virol. 79, 14737-14747. doi: 10.1128/JVI.79.23.1473714747.2005

Merulla, J., Fasana, E., Soldà, T., and Molinari, M. (2013). Specificity and regulation of the endoplasmic reticulum-associated degradation machinery. Traffic 14, 767777. doi: 10.1111/tra. 12068

Meyer, H., Bug, M., and Bremer, S. (2012). Emerging functions of the VCP/p97 AAA-ATPase in the ubiquitin system. Nat. Cell Biol. 14, 117-123. doi: 10.1038/ ncb2407

Meylan, E., Curran, J., Hofmann, K., Moradpour, D., Binder, M., Bartenschlager, R., et al. (2005). Cardif is an adaptor protein in the RIG-I antiviral pathway and is targeted by hepatitis C virus. Nature 437, 1167-1172. doi: 10.1038/nature04193

Monastyrska, I., Ulasli, M., Rottier, P. J. M., Guan, J.-L., Reggiori, F., and de Haan, C. A. M. (2013). An autophagy-independent role for LC3 in equine arteritis virus replication. Autophagy 9, 164-174. doi: 10.4161/auto.22743

Moore, P., Bernardi, K. M., and Tsai, B. (2010). The Erolalpha-PDI redox cycle regulates retro-translocation of cholera toxin. Mol. Biol. Cell 21, 1305-1313. doi: 10.1091/mbc.E09-09-0826

Moriyama, T., and Sorokin, A. (2008). Intracellular trafficking pathway of BK Virus in human renal proximal tubular epithelial cells. Virology 371, 336-349. doi: 10.1016/j.virol.2007.09.030

Muanprasat, C., and Chatsudthipong, V. (2013). Cholera: pathophysiology and emerging therapeutic targets. Future Med. Chem. 5, 781-798. doi: $10.4155 /$ fmc. 13.42 
Mueller, B., Lilley, B. N., and Ploegh, H. L. (2006). SEL1L, the homologue of yeast $\mathrm{Hrd} 3 \mathrm{p}$, is involved in protein dislocation from the mammalian ER. J. Cell Biol. 175, 261-270. doi: 10.1083/jcb.200605196

Müllner, M., Salmons, B., Günzburg, W. H., and Indik, S. (2008). Identification of the Rem-responsive element of mouse mammary tumor virus. Nucleic Acids Res. 36, 6284-6294. doi: 10.1093/nar/gkn608

Nadav, E., Shmueli, A., Barr, H., Gonen, H., Ciechanover, A., and Reiss, Y. (2003). A novel mammalian endoplasmic reticulum ubiquitin ligase homologous to the yeast Hrd1. Biochem. Biophys. Res. Commun. 303, 91-97. doi: 10.1016/S0006291X(03)00279-1

Neil, S. J. D., Zang, T., and Bieniasz, P. D. (2008). Tetherin inhibits retrovirus release and is antagonized by HIV-1 Vpu. Nature 451, 425-430. doi: 10.1038/nature 06553

Nery, F. C., Armata, I. A., Farley, J. E., Cho, J. A., Yaqub, U., Chen, P., et al. (2011). Torsin A participates in endoplasmic reticulum-associated degradation. Nat. Commun. 2:393. doi: 10.1038/ncomms1383

Neu, U., Stehle, T., and Atwood, W. J. (2009). The polyomaviridae: contributions of virus structure to our understanding of virus receptors and infectious entry. Virology 384, 389-399. doi: 10.1016/j.virol.2008.12.021

Neuber, O., Jarosch, E., Volkwein, C., Walter, J., and Sommer, T. (2005). Ubx2 links the Cdc48 complex to ER-associated protein degradation. Nat. Cell Biol. 7 , 993-998. doi: 10.1038/ncb1298

Norkin, L. C., Anderson, H. A., Wolfrom, S. A., and Oppenheim, A. (2002). Caveolar endocytosis of simian virus 40 is followed by brefeldin A-sensitive transport to the endoplasmic reticulum, where the virus disassembles. J. Virol. 76, 5156-5166 doi: 10.1128/JVI.76.10.5156-5166.2002

Nowis, D., McConnell, E., and Wójcik, C. (2006). Destabilization of the VCP-Ufd1$\mathrm{Npl} 4$ complex is associated with decreased levels of ERAD substrates. Exp. Cell Res. 312, 2921-2932. doi: 10.1016/j.yexcr.2006.05.013

Oda, Y., Okada, T., Yoshida, H., Kaufman, R. J., Nagata, K., and Mori, K. (2006). Derlin-2 and Derlin-3 are regulated by the mammalian unfolded protein response and are required for ER-associated degradation. J. Cell Biol. 172, 383-393. doi: $10.1083 /$ jcb.200507057

Okuda-Shimizu, Y., and Hendershot, L. M. (2007). Characterization of an ERAD pathway for nonglycosylated BiP substrates, which require Herp. Mol. Cell 28 , 544-554. doi: 10.1016/j.molcel.2007.09.012

Olivari, S., Cali, T., Salo, K. E. H., Paganetti, P., Ruddock, L. W., and Molinari, M. (2006). EDEM1 regulates ER-associated degradation by accelerating de-mannosylation of folding-defective polypeptides and by inhibiting their covalent aggregation. Biochem. Biophys. Res. Commun. 349, 1278-1284. doi: 10.1016/ j.bbrc.2006.08.186

Olzmann, J. A., and Kopito, R. R. (2011). Lipid droplet formation is dispensable for endoplasmic reticulum-associated degradation. J. Biol. Chem. 286, 27872-27874 doi: 10.1074/jbc.C111.266452

Olzmann, J. A., Kopito, R. R., and Christianson, J. C. (2013). The mammalian endoplasmic reticulum-associated degradation system. Cold Spring Harb. Perspect. Biol. 5. doi: 10.1101/cshperspect.a013185

Oostra, M., te Lintelo, E. G., Deijs, M., Verheije, M. H., Rottier, P. J. M., and de Haan, C. A. M. (2007). Localization and membrane topology of coronavirus nonstructural protein 4 : involvement of the early secretory pathway in replication. J. Virol. 81, 12323-12336. doi: 10.1128/JVI.01506-07

Papadopoulos, V., Baraldi, M., Guilarte, T. R., Knudsen, T. B., Lacapère, J.-J., Lindemann, P., et al. (2006). Translocator protein (18kDa): new nomenclature for the peripheral-type benzodiazepine receptor based on its structure and molecular function. Trends Pharmacol. Sci. 27, 402-409. doi: 10.1016/j.tips.2006. 06.005

Paul, D., and Bartenschlager, R. (2013). Architecture and biogenesis of plus-strand RNA virus replication factories. World J. Virol. 2, 32-48. doi: 10.5501/wjv. v2.i2.32

Pescatore, L. A., Bonatto, D., Forti, F. L., Sadok, A., Kovacic, H., and Laurindo, F. R. M. (2012). Protein disulfide isomerase is required for platelet-derived growth factor-induced vascular smooth muscle cell migration, Noxl NADPH oxidase expression, and RhoGTPase activation. J. Biol. Chem. 287, 29290-29300. doi: 10.1074/jbc.M112.394551

Petris, G., Casini, A., Sasset, L., Cesaratto, F., Bestagno, M., Cereseto, A., et al. (2014). CD4 and BST-2/tetherin proteins retro-translocate from endoplasmic reticulum to cytosol as partially folded and multimeric molecules. J. Biol. Chem. 289, 1-12. doi: 10.1074/jbc.M113.512368
Pye, V. E., Dreveny, I., Briggs, L. C., Sands, C., Beuron, F., Zhang, X., et al. (2006). Going through the motions: the ATPase cycle of p97. J. Struct. Biol. 156, 12-28. doi: $10.1016 /$ j.jsb.2006.03.003

Rapoport, T. A. (2007). Protein translocation across the eukaryotic endoplasmic reticulum and bacterial plasma membranes. Nature 450, 663-669. doi: 10.1038/nature06384

Reggiori, F., Monastyrska, I., Verheije, M. H., Calì, T., Ulasli, M., Bianchi, S., et al. (2010). Coronaviruses Hijack the LC3-I-positive EDEMosomes, ER-derived vesicles exporting short-lived ERAD regulators, for replication. Cell Host Microbe 7, 500-508. doi: 10.1016/j.chom.2010.05.013

Ritz, D., Vuk, M., Kirchner, P., Bug, M., Schütz, S., Hayer, A., et al. (2011). Endolysosomal sorting of ubiquitylated caveolin-1 is regulated by VCP and UBXD1 and impaired by VCP disease mutations. Nat. Cell Biol. 13, 1116-1123. doi: $10.1038 /$ ncb2301

Rodighiero, C., Tsai, B., Rapoport, T. A., and Lencer, W. I. (2002). Role of ubiquitination in retro-translocation of cholera toxin and escape of cytosolic degradation. EMBO Rep. 3, 1222-1227. doi: 10.1093/embo-reports/kvf239

Ruggiano, A., Foresti, O., and Carvalho, P. (2014). Quality control: ER-associated degradation: Protein quality control and beyond. J. Cell Biol. 204, 869-879. doi: $10.1083 /$ jcb. 201312042

Saeed, M., Suzuki, R., Watanabe, N., Masaki, T., Tomonaga, M., Muhammad, A., et al. (2011). Role of the endoplasmic reticulum-associated degradation (ERAD) pathway in degradation of hepatitis $\mathrm{C}$ virus envelope proteins and production of virus particles. J. Biol. Chem. 286, 37264-37273. doi: 10.1074/jbc.M111. 259085

Sauter, D. (2014). Counteraction of the multifunctional restriction factor tetherin. Front. Microbiol. 5:163. doi: 10.3389/fmicb.2014.00163

Schäuble, N., Lang, S., Jung, M., Cappel, S., Schorr, S., Ulucan, Ö., et al. (2012). BiPmediated closing of the Sec61 channel limits $\mathrm{Ca}^{2+}$ leakage from the ER. EMBO J. 31, 3282-3296. doi: 10.1038/emboj.2012.189

Schelhaas, M., Malmström, J., Pelkmans, L., Haugstetter, J., Ellgaard, L., Grünewald, K., et al. (2007). Simian Virus 40 depends on ER protein folding and quality control factors for entry into host cells. Cell 131, 516-529. doi: 10.1016/j.cell.2007.09.038

Schuberth, C., and Buchberger, A. (2005). Membrane-bound Ubx2 recruits Cdc48 to ubiquitin ligases and their substrates to ensure efficient ER-associated protein degradation. Nat. Cell Biol. 7, 999-1006. doi: 10.1038/ncb1299

Schuberth, C., and Buchberger, A. (2008). UBX domain proteins: major regulators of the AAA ATPase Cdc48/p97. Cell. Mol. Life Sci. 65, 2360-2371. doi: 10.1007/s00018-008-8072-8

Seth, R. B., Sun, L., Ea, C.-K., and Chen, Z. J. (2005). Identification and characterization of MAVS, a mitochondrial antiviral signaling protein that activates NF-kappaB and IRF 3. Cell 122, 669-682. doi: 10.1016/j.cell.2005. 08.012

Shenkman, M., Groisman, B., Ron, E., Avezov, E., Hendershot, L. M., and Lederkremer, G. Z. (2013). A shared endoplasmic reticulum-associated degradation pathway involving the EDEM1 protein for glycosylated and nonglycosylated proteins. J. Biol. Chem. 288, 2167-2178. doi: 10.1074/jbc.M112.438275

Skaar, J. R., Pagan, J. K., and Pagano, M. (2013). Mechanisms and function of substrate recruitment by F-box proteins. Nat. Rev. Mol. Cell Biol. 14, 369-381. doi: 10.1038/nrm3582

Smith, M. H., Ploegh, H. L., and Weissman, J. S. (2011). Road to ruin: targeting proteins for degradation in the endoplasmic reticulum. Science 334, 1086-1090. doi: 10.1126/science.1209235

Sowa, M. E., Bennett, E. J., Gygi, S. P., and Harper, J. W. (2009). Defining the human deubiquitinating enzyme interaction landscape. Cell 138, 389-403. doi: 10.1016/j.cell.2009.04.042

Spangler, B. D. (1992). Structure and function of cholera toxin and the related Escherichia coli heat-labile enterotoxin. Microbiol. Rev. 56, 622-647.

Stagg, H. R., Thomas, M., van den Boomen, D., Wiertz, E. J. H. J., Drabkin, H. A., Gemmill, R. M., et al. (2009). The TRC8 E3 ligase ubiquitinates MHC class I molecules before dislocation from the ER. J. Cell Biol. 186, 685-692. doi: 10.1083/ jcb. 200906110

Stertz, S., Reichelt, M., Spiegel, M., Kuri, T., Martínez-Sobrido, L., García-Sastre, A., et al. (2007). The intracellular sites of early replication and budding of SARScoronavirus. Virology 361, 304-315. doi: 10.1016/j.virol.2006.11.027

Story, C. M., Furman, M. H., and Ploegh, H. L. (1999). The cytosolic tail of class I MHC heavy chain is required for its dislocation by the human cytomegalovirus 
US2 and US11 gene products. Proc. Natl. Acad. Sci. U.S.A. 96, 8516-8521. doi: 10.1073/pnas.96.15.8516

Strebel, K. (2013). HIV accessory proteins versus host restriction factors. Curr. Opin. Virol. 3, 692-699. doi: 10.1016/j.coviro.2013.08.004

Sun, S., Shi, G., Han, X., Francisco, A. B., Ji, Y., Mendonça, N., et al. (2014). Sel1L is indispensable for mammalian endoplasmic reticulum-associated degradation, endoplasmic reticulum homeostasis, and survival. Proc. Natl. Acad. Sci. U.S.A. 111, E582-E591. doi: 10.1073/pnas.1318114111

Taxis, C., Hitt, R., Park, S.-H., Deak, P. M., Kostova, Z., and Wolf, D. H. (2003). Use of modular substrates demonstrates mechanistic diversity and reveals differences in chaperone requirement of ERAD. J. Biol. Chem. 278, 35903-35913. doi: 10.1074/jbc.M301080200

Thibault, G., and Ng, D. T. W. (2012). The endoplasmic reticulum-associated degradation pathways of budding yeast. Cold Spring Harb. Perspect. Biol. 4. doi: $10.1101 /$ cshperspect.a013193

Tsai, B., and Qian, M. (2010). Cellular entry of polyomaviruses. Curr. Top. Microbiol. Immunol. 343, 177-194. doi: 10.1007/82_2010_38

Tsai, B., Rodighiero, C., Lencer, W. I., and Rapoport, T. A. (2001). Protein disulfide isomerase acts as a redox-dependent chaperone to unfold cholera toxin. Cell 104 937-948. doi: 10.1016/S0092-8674(01)00289-6

Tsai, Y. C., and Weissman, A. M. (2012). A ubiquitin-binding rhomboid protease aimed at ERADication. Dev. Cell 23, 454-456. doi: 10.1016/j.devcel.2012. 08.015

Tubo, N. J., and Jenkins, M. K. (2014). CD4+ T cells: guardians of the phagosome. Clin. Microbiol. Rev. 27, 200-213. doi: 10.1128/CMR.00097-13

Ushioda, R., Hoseki, J., and Nagata, K. (2013). Glycosylation-independent ERAD pathway serves as a backup system under ER stress. Mol. Biol. Cell 24, 3155-3163. doi: 10.1091/mbc.E13-03-0138

van der Veen, A. G., and Ploegh, H. L. (2012). Ubiquitin-like proteins. Annu. Rev. Biochem. 81, 323-357. doi: 10.1146/annurev-biochem-093010-153308

Vembar, S. S., and Brodsky, J. L. (2008). One step at a time: endoplasmic reticulumassociated degradation. Nat. Rev. Mol. Cell Biol. 9, 944-957. doi: 10.1038/ nrm 2546

Verchot, J. (2014). The ER quality control and ER associated degradation machineries are vital for viral pathogenesis. Front. Plant Sci. 5:66. doi: 10.3389/fpls.2014. 00066

Voss, M., Schröder, B., and Fluhrer, R. (2013). Mechanism, specificity, and physiology of signal peptide peptidase (SPP) and SPP-like proteases. Biochim. Biophys. Acta 1828, 2828-2839. doi: 10.1016/j.bbamem.2013.03.033

Wakana, Y., Takai, S., Nakajima, K.-I., Tani, K., Yamamoto, A., Watson, P., et al. (2008). Bap31 is an itinerant protein that moves between the peripheral endoplasmic reticulum (ER) and a juxtanuclear compartment related to ERassociated Degradation. Mol. Biol. Cell 19, 1825-1836. doi: 10.1091/mbc.E0708-0781

Wang, X., Connors, R., Harris, M. R., Hansen, T. H., and Lybarger, L. (2005) Requirements for the selective degradation of endoplasmic reticulum-resident major histocompatibility complex class I proteins by the viral immune evasion molecule mK3. J. Virol. 79, 4099-4108. doi: 10.1128/JVI.79.7.4099-41 08.2005

Wang, X., Herr, R. A., Chua, W.-J., Lybarger, L., Wiertz, E. J. H. J., and Hansen, T. H. (2007). Ubiquitination of serine, threonine, or lysine residues on the cytoplasmic tail can induce ERAD of MHC-I by viral E3 ligase mK3. J. Cell Biol. 177, 613-624. doi: $10.1083 /$ jcb. 200611063

Wang, X., Herr, R. A., Rabelink, M., Hoeben, R. C., Wiertz, E. J. H. J., and Hansen, T. H. (2009). Ube2j2 ubiquitinates hydroxylated amino acids on ERassociated degradation substrates. J. Cell Biol. 187, 655-668. doi: 10.1083/jcb.200 908036

Wang, X., Ye, Y., Lencer, W., and Hansen, T. H. (2006). The viral E3 ubiquitin ligase $\mathrm{mK} 3$ uses the Derlin/p97 endoplasmic reticulum-associated degradation pathway to mediate down-regulation of major histocompatibility complex class I proteins. J. Biol. Chem. 281, 8636-8644. doi: 10.1074/jbc.M513920200
Wiertz, E. J., Tortorella, D., Bogyo, M., Yu, J., Mothes, W., Jones, T. R., et al. (1996) Sec61-mediated transfer of a membrane protein from the endoplasmic reticulum to the proteasome for destruction. Nature 384, 432-438. doi: 10.1038/384432a0

Willems, S. H., Tape, C. J., Stanley, P. L., Taylor, N. A., Mills, I. G., Neal, D. E., et al. (2010). Thiol isomerases negatively regulate the cellular shedding activity of ADAM17. Biochem. J. 428, 439-450. doi: 10.1042/BJ20100179

Willey, R. L., Maldarelli, F., Martin, M. A., and Strebel, K. (1992). Human immunodeficiency virus type $1 \mathrm{Vpu}$ protein regulates the formation of intracellular gp160-CD4 complexes. J. Virol. 66, 226-234.

Williams, J. M., Inoue, T., Banks, L., and Tsai, B. (2013). The ERdj5-Sel1L complex facilitates cholera toxin retrotranslocation. Mol. Biol. Cell 24, 785-795. doi: 10.1091/mbc.E12-07-0522

Winkeler, A., Gödderz, D., Herzog, V., and Schmitz, A. (2003). BiP-dependent export of cholera toxin from endoplasmic reticulum-derived microsomes. FEBS Lett. 554, 439-442. doi: 10.1016/S0014-5793(03)01217-1

Wolf, D. H., and Stolz, A. (2012). The Cdc48 machine in endoplasmic reticulum associated protein degradation. Biochim. Biophys. Acta 1823, 117-124. doi: 10.1016/j.bbamcr.2011.09.002

Xu, L.-G., Wang, Y.-Y., Han, K.-J., Li, L.-Y., Zhai, Z., and Shu, H.-B. (2005). VISA is an adapter protein required for virus-triggered IFN-beta signaling. Mol. Cell 19, 727-740. doi: 10.1016/j.molcel.2005.08.014

Ye, Y., Meyer, H. H., and Rapoport, T. A. (2003). Function of the p97-Ufd1-Npl4 complex in retrotranslocation from the ER to the cytosol: dual recognition of nonubiquitinated polypeptide segments and polyubiquitin chains. J. Cell Biol. 162, 71-84. doi: 10.1083/jcb.200302169

Ye, Y., Shibata, Y., Kikkert, M., van Voorden, S., Wiertz, E., and Rapoport, T. A. (2005). Recruitment of the p97 ATPase and ubiquitin ligases to the site of retrotranslocation at the endoplasmic reticulum membrane. Proc. Natl. Acad. Sci. U.S.A. 102, 14132-14138. doi: 10.1073/pnas.0505006102

Ye, Y., Shibata, Y., Yun, C., Ron, D., and Rapoport, T. A. (2004). A membrane protein complex mediates retro-translocation from the ER lumen into the cytosol. Nature 429, 841-847. doi: 10.1038/nature02656

Yoshida, Y. (2007). F-box proteins that contain sugar-binding domains. Biosci. Biotechnol. Biochem. 71, 2623-2631. doi: 10.1271/bbb.70074

Yoshida, Y., Adachi, E., Fukiya, K., Iwai, K., and Tanaka, K. (2005). Glycoproteinspecific ubiquitin ligases recognize $\mathrm{N}$-glycans in unfolded substrates. EMBO Rep. 6, 239-244. doi: 10.1038/sj.embor.7400351

Zapp, M. L., and Green, M. R. (1989). Sequence-specific RNA binding by the HIV-1 Rev protein. Nature 342, 714-716. doi: 10.1038/342714a0

Zhou, T., Dang, Y., and Zheng, Y.-H. (2014). The mitochondrial translocator protein, TSPO, inhibits HIV-1 envelope glycoprotein biosynthesis via the endoplasmic reticulum-associated protein degradation pathway. J. Virol. 88, 3474-3484. doi: 10.1128/JVI.03286-13

Zinzula, L., and Tramontano, E. (2013). Strategies of highly pathogenic RNA viruses to block dsRNA detection by RIG-I-like receptors: hide, mask, hit. Antiviral Res. 100, 615-635. doi: 10.1016/j.antiviral.2013.10.002

Conflict of Interest Statement: The authors declare that the research was conducted in the absence of any commercial or financial relationships that could be construed as a potential conflict of interest.

Received: 09 May 2014; accepted: 16 June 2014; published online: 03 July 2014. Citation: Byun H, Gou Y, Zook A, Lozano MM and Dudley JP (2014) ERAD and how viruses exploit it. Front. Microbiol. 5:330. doi: 10.3389/fmicb.2014.00330

This article was submitted to Virology, a section of the journal Frontiers in Microbiology. Copyright (c) 2014 Byun, Gou, Zook, Lozano and Dudley. This is an open-access article distributed under the terms of the Creative Commons Attribution License (CC BY). The use, distribution or reproduction in other forums is permitted, provided the original author(s) or licensor are credited and that the original publication in this journal is cited, in accordance with accepted academic practice. No use, distribution or reproduction is permitted which does not comply with these terms. 